\title{
MODELLING INFLATION IN AUSTRALIA
}

\author{
Gordon de Brouwer and Neil R. Ericsson
}

\author{
Research Discussion Paper \\ 9510
}

\author{
November 1995 \\ Economic Analysis and Economic Research Departments \\ Reserve Bank of Australia
}

The views expressed herein are those of the authors and do not necessarily reflect those of the Reserve Bank of Australia, the Board of Governors of the Federal Reserve System, or other members of their staffs. 


\begin{abstract}
This paper develops an empirically constant, data-coherent, error correction model for inflation in Australia. The level of consumer prices is a mark-up over domestic and import costs, with adjustments for dynamics and relative aggregate demand. We address issues of cointegration, general to specific modelling, dynamic specification, model evaluation and testing, parameter constancy, and exogeneity. We also test this model against existing models of Australian prices: this model encompasses (but is not encompassed by) the existing models.
\end{abstract}




\section{TABLE OF CONTENTS}

1. Introduction 1

2. A Conceptual Framework 2

3. The Data 4

4. Integration and Cointegration 10

$\begin{array}{lll}4.1 & \text { Integration } & 10\end{array}$

$\begin{array}{lll}4.2 & \text { Cointegration } & 12\end{array}$

5. A Single Equation Model of Inflation 17

5.1 Autoregressive Distributed Lags, ECMs, and Long-Run Solutions 17

5.2 General to Specific Modelling 21

6. The Model's Properties 23

6.1 Long-Run Properties of the Model 23

6.2 Dynamic Properties of the Model 27

6.3 Statistical Properties of the Model 32

6.4 Caveats 34

7. Encompassing and Forecasting 35

7.1 Encompassing Alternative Models of Inflation 35

$\begin{array}{lll}7.2 & \text { Forecasting } & 39\end{array}$

8. Conclusions 40

Appendix 1: Data Definitions 43

Appendix 2: Design of the Empirical ECM 49

Appendix 3: An Alternative Model of the CPI 57

$\begin{array}{ll}\text { References } & 60\end{array}$ 


\title{
MODELLING INFLATION IN AUSTRALIA
}

\author{
Gordon de Brouwer and Neil R. Ericsson*
}

\section{INTRODUCTION}

In the 1980s, the Australian inflation rate averaged around 8 per cent a year. At the beginning of the 1990s, the inflation rate fell substantially and now averages a much more moderate 2 per cent a year. This path of inflation has occurred alongside major changes in the Australian economy, including substantial reductions in tariffs, a shift to a more flexible and productivity-based system for setting wages, and a greater focus on international competitiveness. Moreover, the Reserve Bank of Australia has made a strong commitment to the preservation of low inflation, seeking to maintain an underlying inflation rate of around 2 to 3 per cent; see Reserve Bank of Australia (1994a, p. 3).

To understand better the behaviour of inflation and the role that a central bank may play in its determination, this paper develops an empirical model of the Australian consumer price index (CPI). The underlying economic theory is a mark-up model for prices, but the resulting empirical model also has elements relating to purchasing power parity and the Phillips curve. The empirical model clarifies the relative importance of factors determining consumer price inflation. Further, the structure of the inflationary

The authors are staff economists in the Economics Group, Reserve Bank of Australia, Sydney, Australia and the Division of International Finance, Federal Reserve Board, Washington, D.C., United States respectively. The views expressed in this paper are solely the responsibility of the authors and should not be interpreted as reflecting those of the Reserve Bank of Australia, the Board of Governors of the Federal Reserve System, or other members of their staffs. The second author gratefully acknowledges the generous hospitality of the staff at the Reserve Bank of Australia, where he was visiting when much of this research was undertaken. We wish to thank Darren Flood and John Irons for valuable research assistance; Palle Anderson, Carol Bertaut, David Bowman, Julia Campos, Tony Hall, Dale Henderson, David Hendry, Katarina Juselius, Deb Lindner, Jaime Marquez, Doug McTaggart, and Adrian Pagan for helpful comments and discussions; Tony Hall for providing the data in McTaggart and Hall (1993); and Jurgen Doornik and David Hendry for providing us with a beta-test version of PcGive 9.00. All numerical results were obtained using PcGive Professional Versions 8.10 and 9.00 ß01; cf. Doornik and Hendry (1994). This paper is being simultaneously circulated as Research Discussion Paper No. 9510 by the Reserve Bank of Australia and International Finance Discussion Paper No. 530 by the Board of Governors of the Federal Reserve System. 
process in Australia does not appear to have changed over the 1980s and 1990s. Rather, the recent fall in inflation is explained in terms of changes in the determinants of inflation itself.

Sections 2 and 3 briefly describe the economic theory and the data. Using quarterly series over 1977-1993, Section 4 analyses the CPI and its long-run determinants as a system, testing for and finding cointegration between them. Weak exogeneity also appears valid, so Sections 5-7 model the CPI as a single-equation conditional error correction model, obtained from an autoregressive distributed lag for the CPI. The error correction model is highly parsimonious and empirically constant, with an equation standard error of $0.25 \%$; and its economic interpretation is straightforward. As an error correction model, this model of Australian CPI captures longrun effects that were ignored in some previous models, which were in first differences only. Including the error correction term in the empirical model of Australian CPI ties the model more closely to its theoretical underpinnings and improves the goodness-of-fit. Section 8 concludes. Appendix 1 describes the construction of the data; Appendix 2 documents the design of the empirical error correction model; and Appendix 3 evaluates an alternative, slightly more complicated model.

\section{A CONCEPTUAL FRAMEWORK}

While there are numerous theories and models of inflation, the enduring representation of the inflation process in Australia has been the mark-up model; see, for example, Richards and Stevens (1987). The mark-up model has a long-standing and continuing presence in economics generally; see Duesenberry (1950) and Franz and Gordon (1993) inter alia. The mark-up model is used throughout this paper, and it is general enough to embed several other well-known models, as noted below. This section describes the mark-up model underlying this paper's empirical analysis.

In the long run, the domestic general price level is a mark-up over total unit costs, including unit labour costs, import prices, and energy prices. Assuming linear homogeneity, the long-run relation of the domestic consumer price level to its determinants is:

$$
P=\mu \cdot\left(U L C^{\gamma}\right)\left(I P^{\delta}\right)\left(P E T^{\kappa}\right)
$$


The data are the underlying consumer price index $(P)$, an index of the nominal cost of labour per unit of output $(U L C)$, an index of tariff-adjusted import prices in domestic currency $(I P)$, and an index of petrol prices in domestic currency $(P E T)$. The elasticities of the consumer price index with respect to $U L C, I P$, and $P E T$ are $\gamma, \delta$, and $\kappa$, respectively, each of which is hypothesized to be greater than or equal to zero. The value $\mu-1$ is the retail mark-up over costs, and both the mark-up and costs may vary over the cycle. ${ }^{1}$

In practice, (1) is expressed in its log-linear form:

$$
p=\ln (\mu)+\gamma \cdot u l c+\delta \cdot i p+\kappa \cdot p e t,
$$

where logarithms of variables are denoted by lower case letters. The log-linear form is used in the error correction model below. Linear homogeneity implies the following testable hypothesis:

$$
\gamma+\delta+\kappa=1
$$

which is unit homogeneity in all prices. Under that hypothesis, (2) can be rewritten as:

$$
0=\ln (\mu)+\gamma(u l c-p)+\delta(i p-p)+\kappa(p e t-p)
$$

which links real prices in the labour, foreign goods, and energy markets. This representation will be particularly useful in interpreting the empirical error correction model in the context of multiple markets influencing prices; cf. Juselius (1992) and Metin (1994). Additionally, through the term $(i p-p)$, (4) clarifies how the hypothesis of purchasing power parity is embedded in the mark-up model in (1). As discussed later, the empirical implementation also has ties to the Phillips curve by allowing the mark-up $\mu-1$ to depend upon the output gap.

1 The nominal cost of capital per unit of output was also included in initial modelling of the CPI. However, no long- or short-run effects of unit capital costs on the CPI were found, so unit capital costs are excluded from discussion in the remainder of this paper. Appendix 1 describes the measure of unit capital costs used. 


\section{THE DATA}

This section describes the data available and considers some of their basic properties. All data are quarterly, spanning 1976(3)-1993(3). Allowing for lags and transformations, estimation is over 1977(3)-1993(3) unless otherwise noted. Appendix 1 discusses in detail the definition and construction of the data.

The consumer price index is the central series of this study, and choosing an appropriate measure for it is complicated. The most publicly visible measure is the headline CPI (denoted $P^{h}$ ), published by the Australian Bureau of Statistics. However, the headline CPI includes a number of components that are subject to strong transitory fluctuations, that are controlled or influenced by the official sector, or that are unambiguously determined outside the Australian economy. While these components affect the Australian consumer, they are not necessarily readily modelled. While no final judgment exists as to which components should be excluded, this paper models one commonly used "underlying CPI" series, which is adjusted for such components. This underlying CPI (denoted $P$ ) is calculated as the headline CPI net of fresh fruit and vegetables, mortgage interest and consumer credit charges, automotive fuel, and health services. ${ }^{2}$ In this paper, "CPI" always means this underlying CPI unless explicitly noted otherwise.

Figure 1 plots the quarterly inflation rates for underlying and headline CPI, denoted $\Delta p$ and $\Delta p^{h}{ }^{3}$ The most noticeable differences between the two series are in 1976 and 1984, when large changes in the cost of health services occurred. Figures 2 and 3 plot the log of the CPI and its annual growth rate respectively.

Three additional series are of interest: $U L C, I P$, and PET. Figures 2-7 plot the logs of these indices and their annual growth rates, contrasting them with the corresponding transformations of the CPI. Over the sample as a whole, unit labour costs and import prices fall relative to the CPI,

2 See Reserve Bank of Australia (1994b) for a discussion of related issues and various measurements.

3 The difference operator $\Delta$ is defined as $(1-L)$, where the lag operator $L$ shifts a variable one period into the past. Hence, for $x_{t}$ (a variable $x$ at time $t$ ), $L x_{t}=x_{t-1}$ and so $\Delta x_{t}=x_{t}-x_{t-1}$. More generally, $\Delta_{j}^{i} x_{t}=\left(1-L^{j}\right)^{i} x_{t}$. If $i$ (or $j$ ) is undefined, it is taken to be unity. 
Figure 1: The underlying CPI inflation rate $\Delta p(-)$ and the headline CPI inflation rate $\Delta p^{h}(\cdots)$.

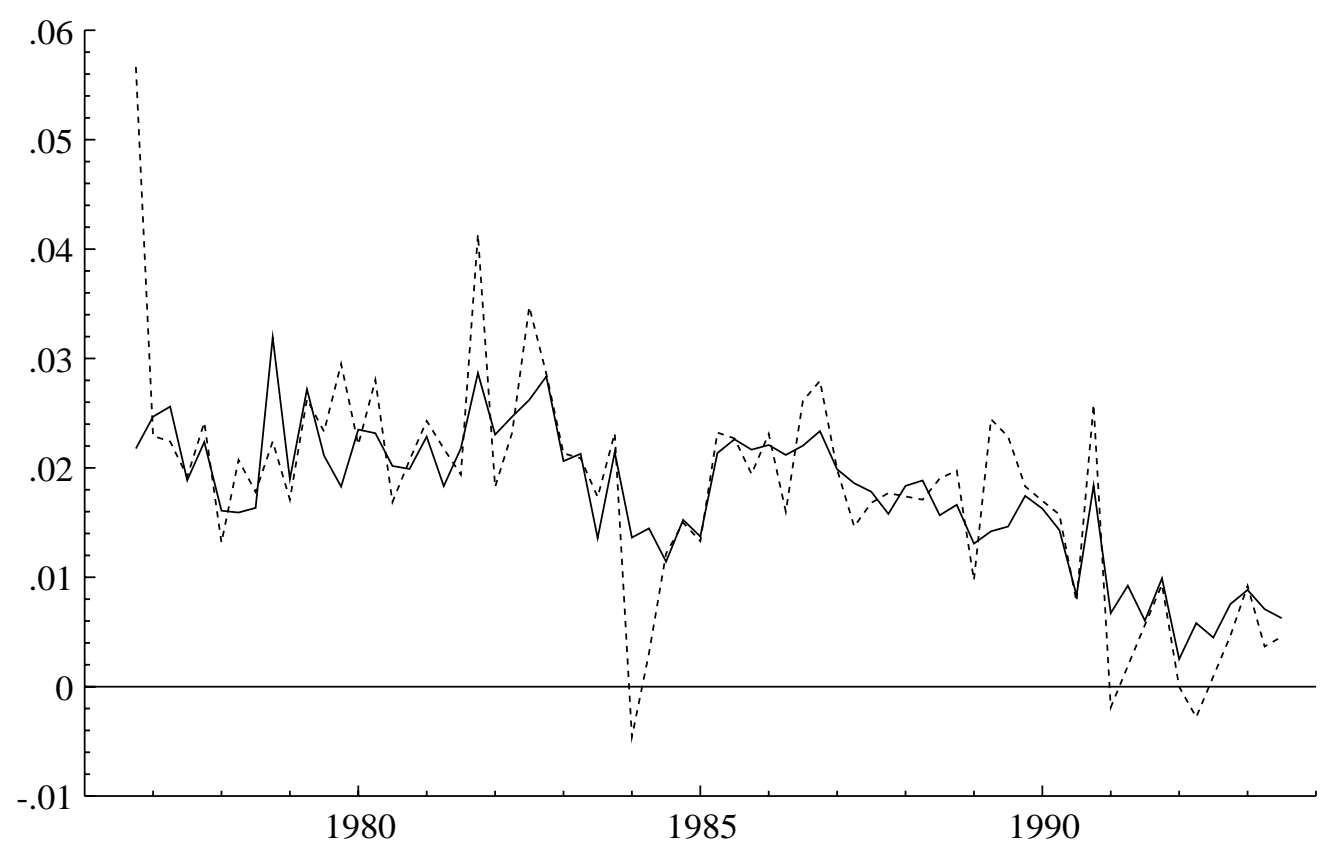

whereas petrol prices rise relative to the CPI. To make these trends more apparent, Figure 8 plots real unit labour costs and real import prices, and Figure 9 plots real petrol prices. In Figure 8, the two series tend to move in opposite directions by roughly the same magnitude, while having similar downward trends of approximately $1 \%$ per annum. Both features are captured more formally in Sections 4.2, 5.2, and 6.1: the first by the nearly equal coefficients on nominal unit labour costs and import prices in the cointegrating vector, the second by inflation's presence in the dynamic steady-state solution for the CPI. ${ }^{4}$ In Figure 9, the time series for real petrol prices reflects the OPEC oil price increase in 1979, the fall in real oil prices in the latter half of the 1980s, and the dramatic but temporary increase in oil prices associated with the Gulf War. Further, the growth rates of these possible determinants for the CPI are all much more volatile than the CPI itself: see Figures 3, 5, and 7. Any mark-up model attempting to explain

4 To portray clearly the relative movements of $u l c-p$ and $i p-p$ in Figure 8, the mean of $i p-p$ is adjusted when the series are plotted. The means of $u l c-p$ and $i p-p$ are 0.047 and 0.183 respectively, so -0.136 is added to $i p-p$ to bring its mean in line with that of $u l c-p$. Economically, such adjustment is unimportant: these variables are indices and are in logs. Econometrically, the constant term in a regression induces a similar adjustment. 
Figure 2: The logs of the consumer price index $p(-)$ and unit labour costs ulc $(\cdots)$.

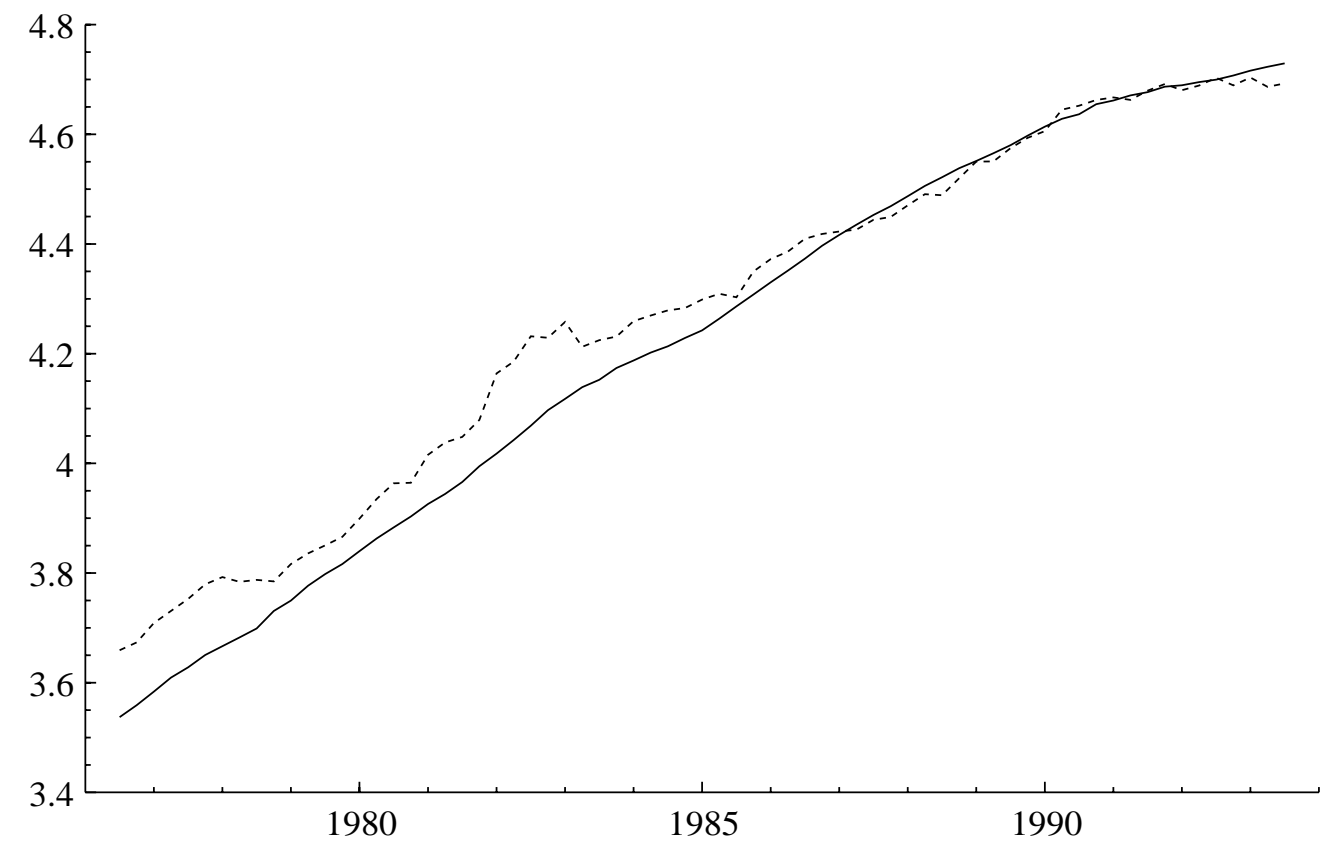

Figure 3: Annual growth rates for the consumer price index $\Delta_{4} p(-)$ and unit labour costs $\Delta_{4} u l c(\cdots)$.

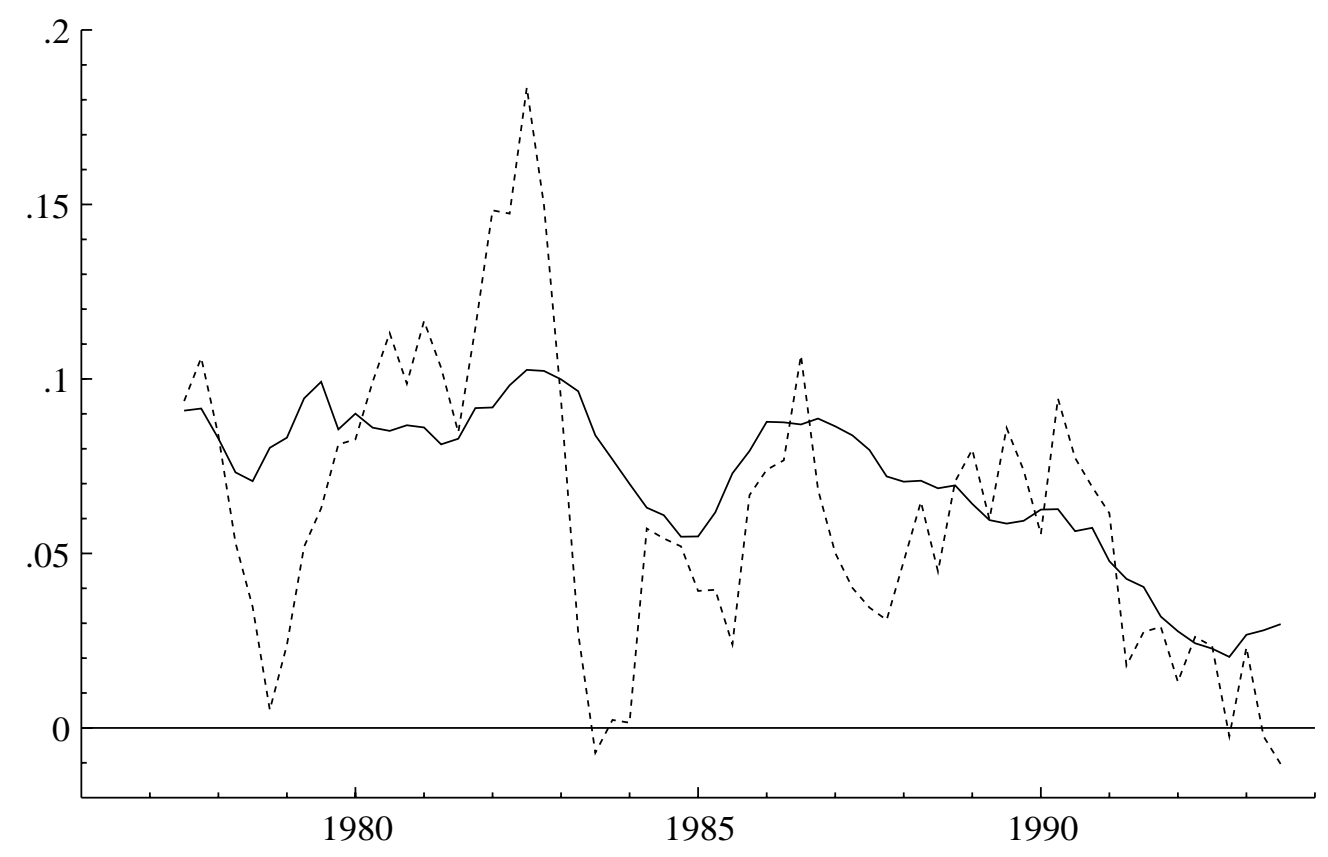


Figure 4: The logs of the consumer price index $p(-)$ and tariff-adjusted import prices $i p(\cdots)$.

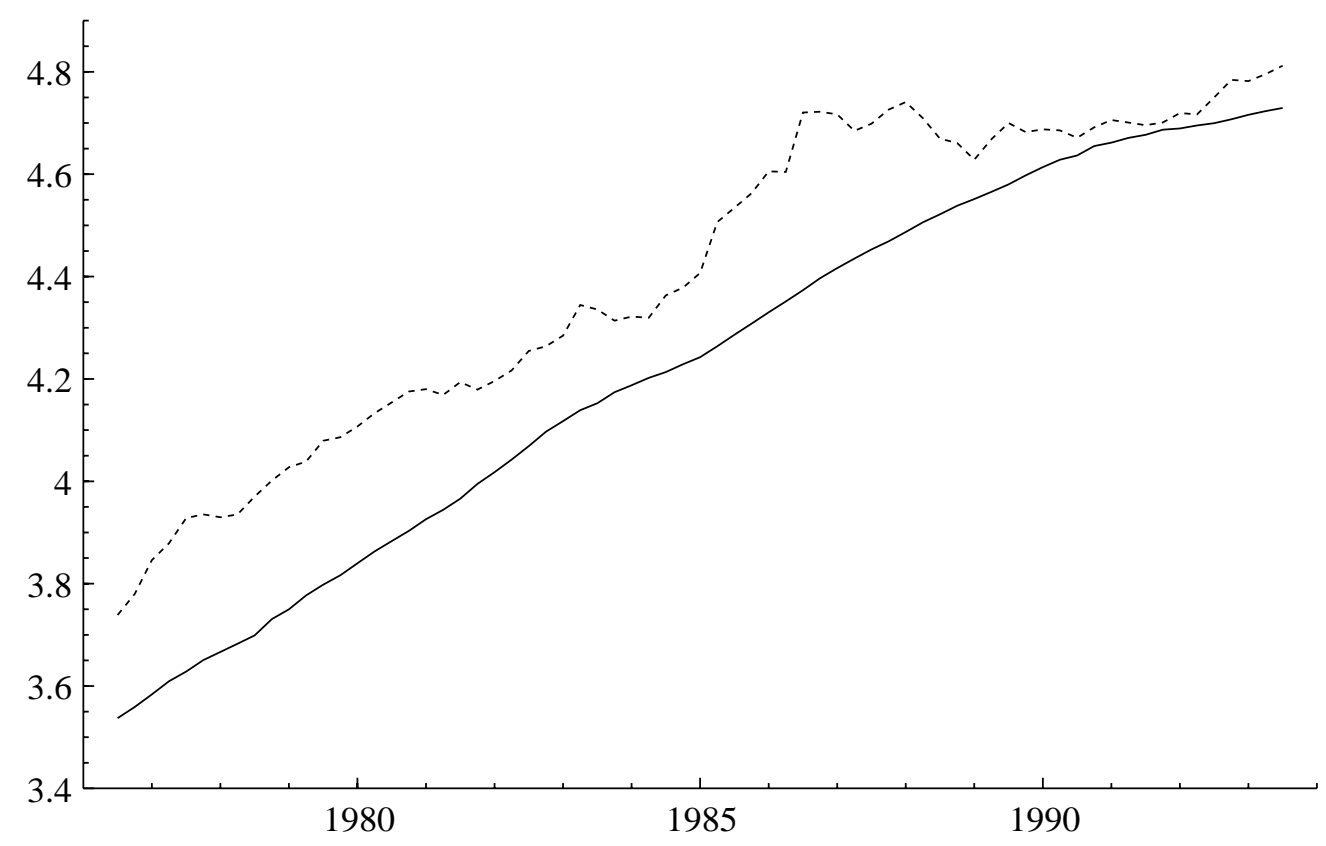

Figure 5: Annual growth rates for the consumer price index $\Delta_{4} p\left(\right.$ (一) and tariff-adjusted import prices $\Delta_{4} i p(\cdots)$.

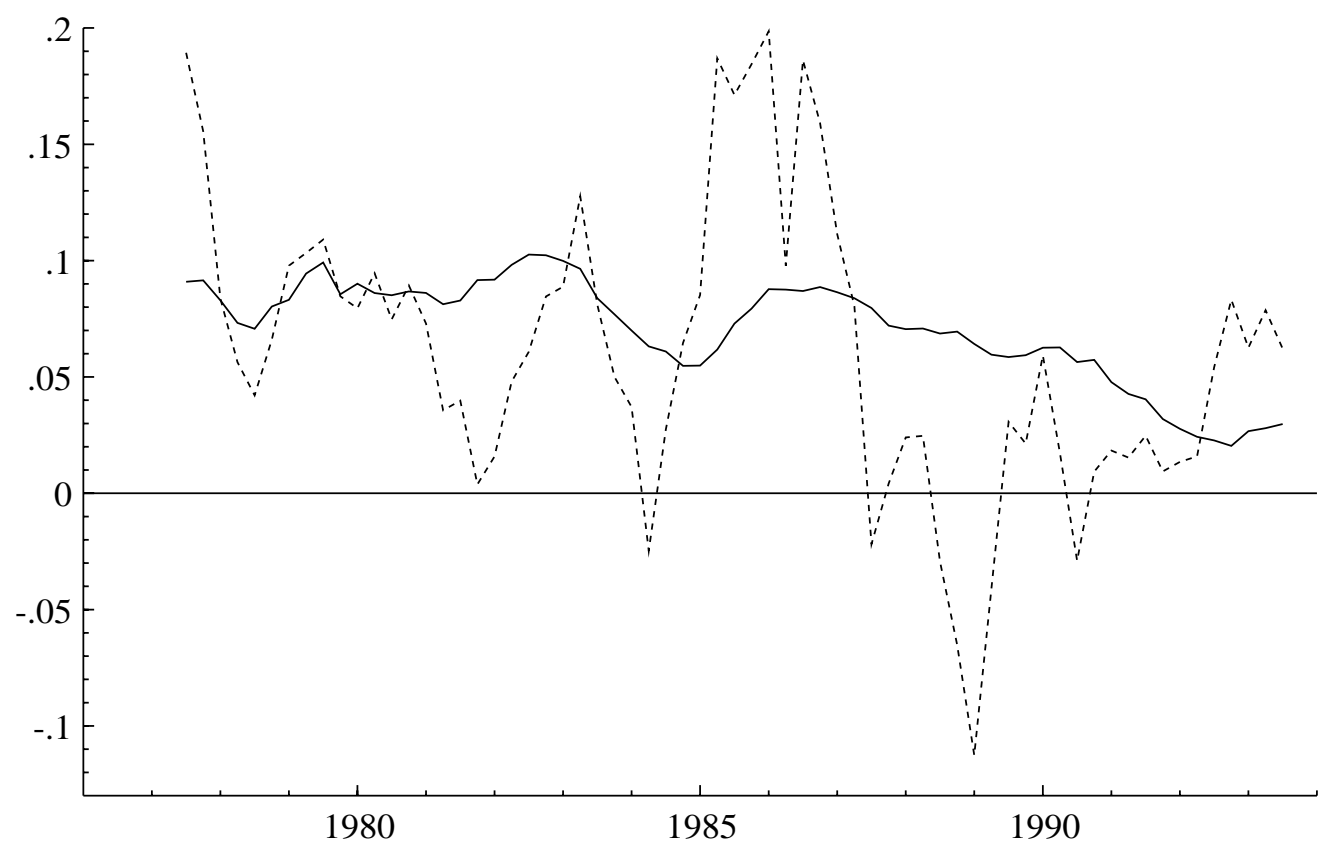


Figure 6: The logs of the consumer price index $p(-)$ and petrol prices pet $(\cdots)$.

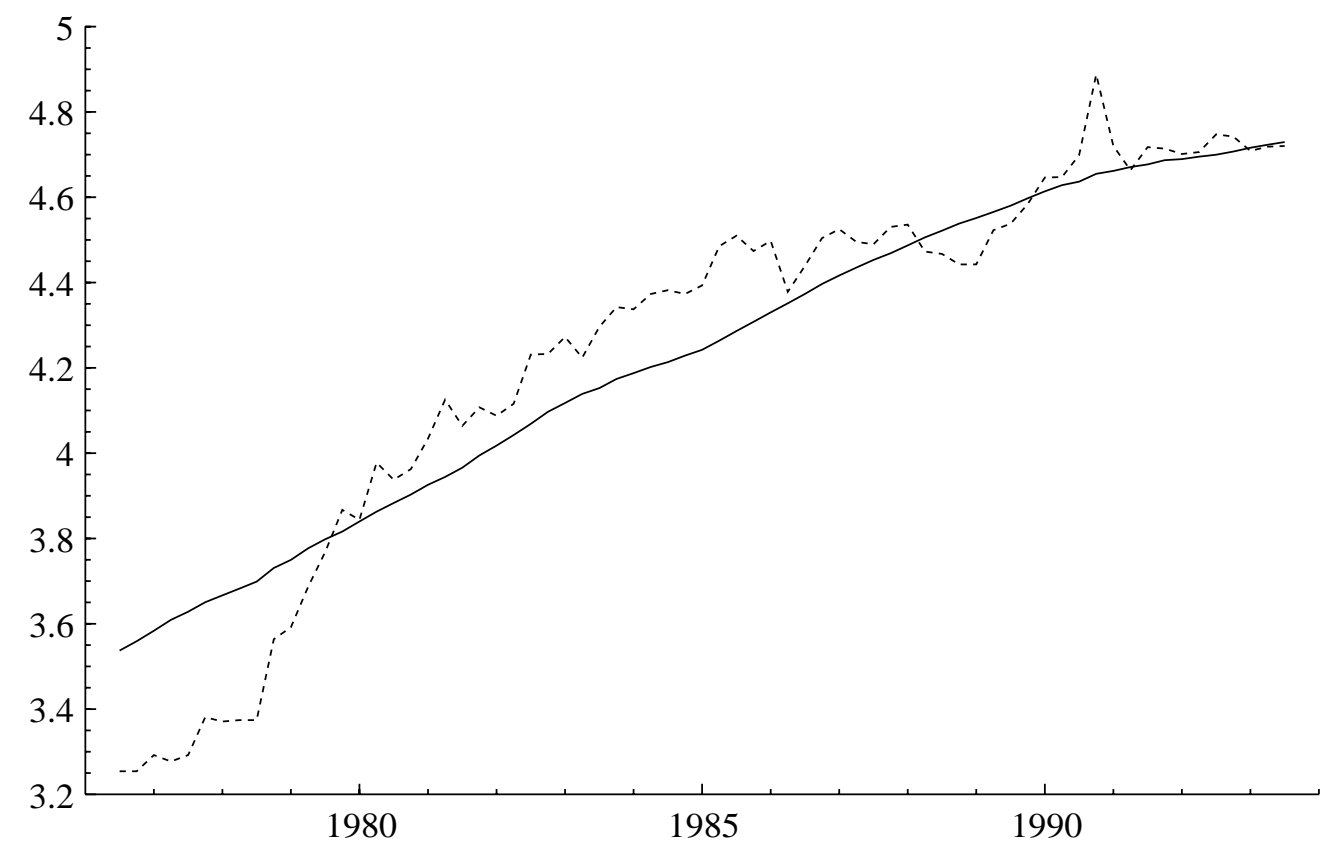

Figure 7: Annual growth rates for the consumer price index $\Delta_{4} p(-)$ and petrol prices $\Delta_{4}$ pet $(\cdots)$.

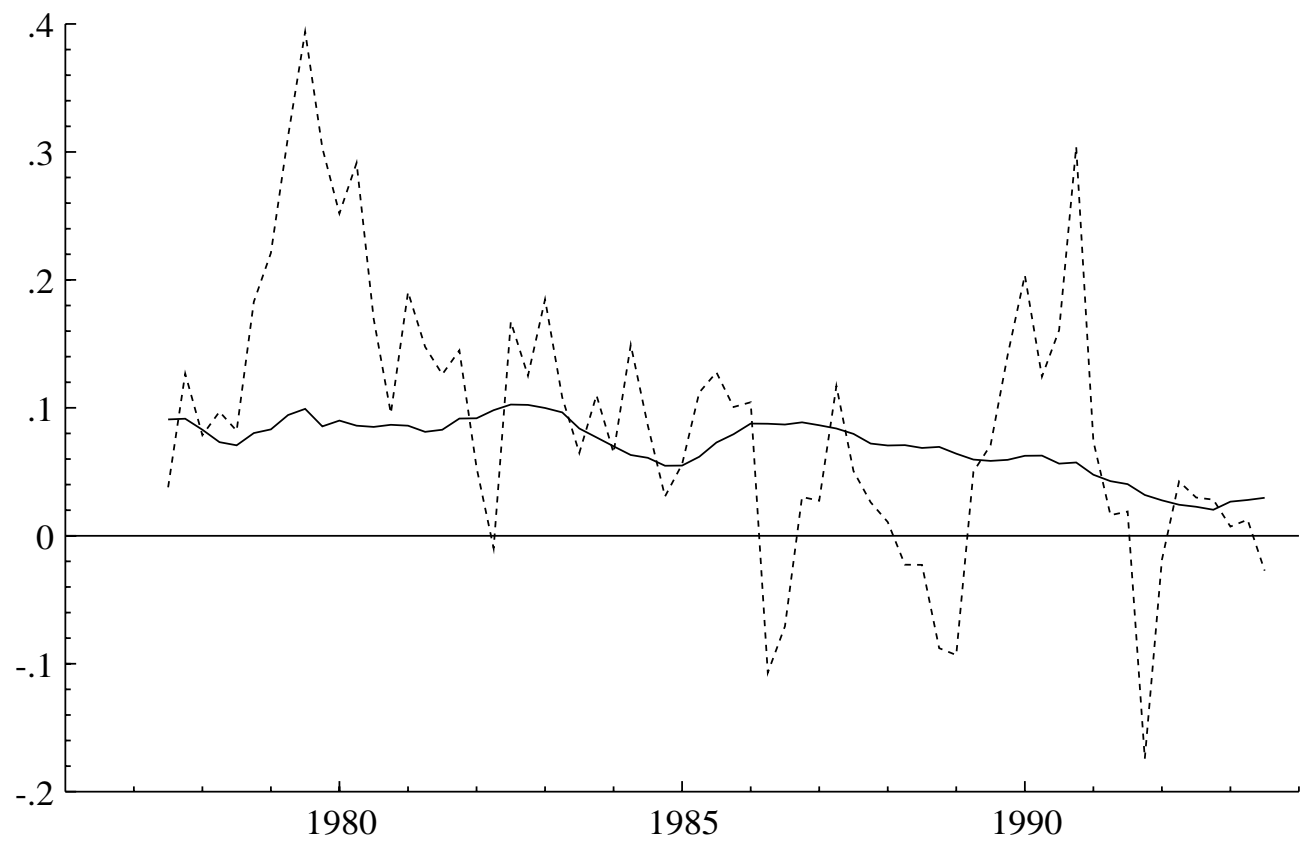


Figure 8: Real unit labour costs $u l c-p(-)$ and real tariff-adjusted import prices $i p-p(\cdots)$.

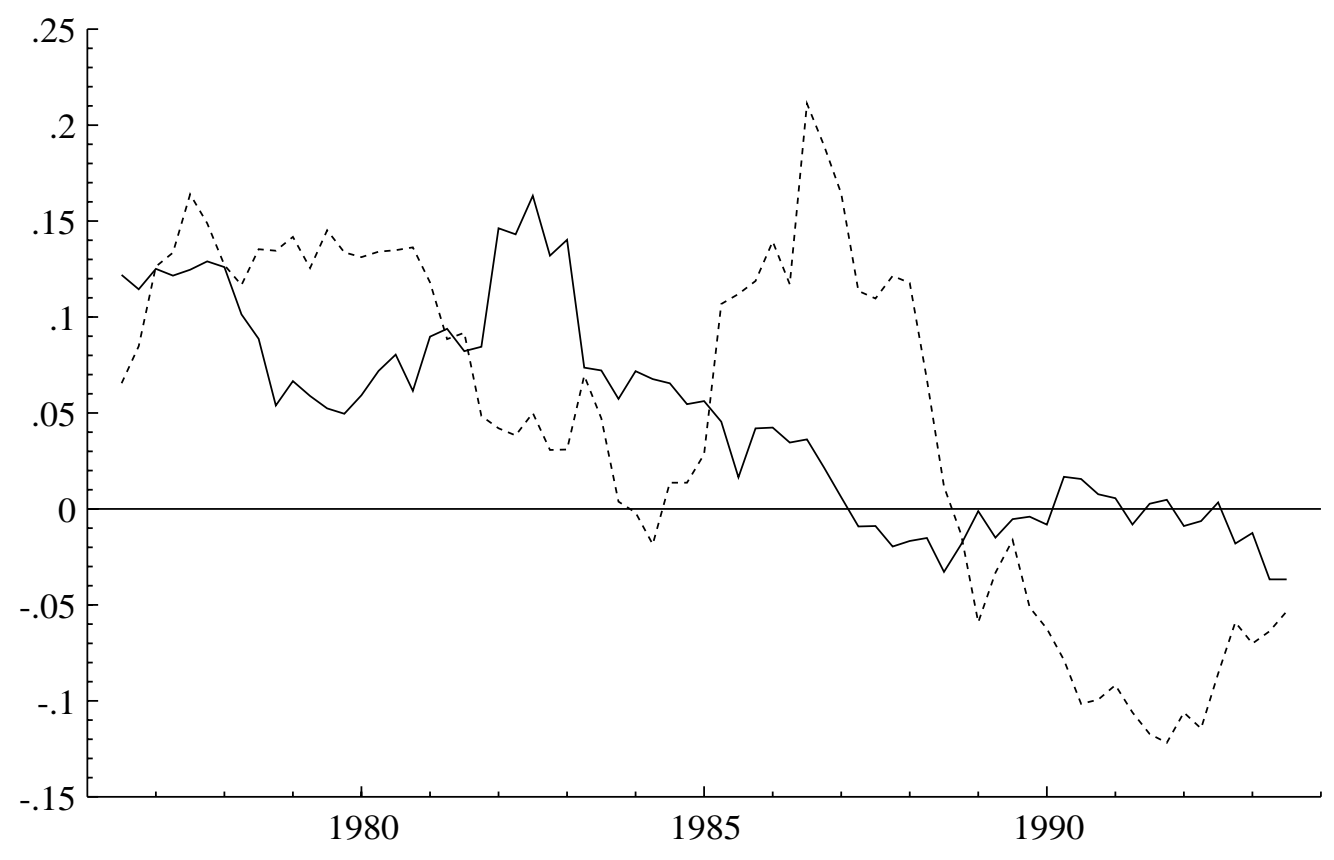

Figure 9: Real petrol prices $p e t-p(-)$.

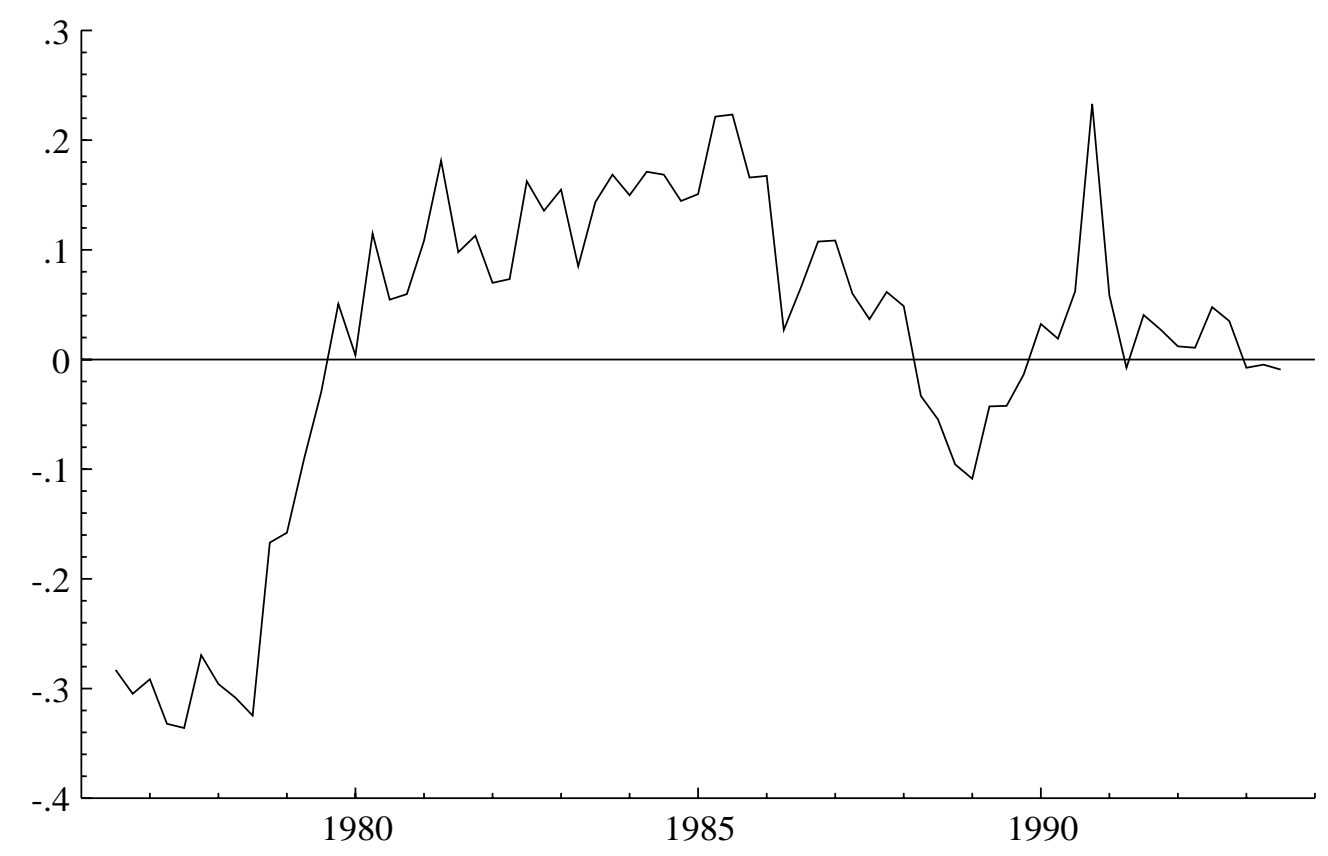


the CPI would need to explain these dramatic differences in variability.

One more series is of interest, private final demand $(Y)$. This series is used to construct a proxy for the output gap, as measured by the residual $y^{\text {res }}$ from regressing $y$ on a constant and a trend $t$. Empirically, regression obtains:

$$
y_{t}^{r e s}=y_{t}-10.741-0.0069428 t
$$

where the estimation sample is 1976(3)-1993(3) and a subscript $t$ denotes time. Equation (5) implies that private final demand is growing at approximately $2.8 \%$ per annum on average. The output gap is discussed at greater length in Appendix 3.

The CPI and petrol prices are seasonally unadjusted, whereas unit labour costs, import prices, and private final demand are seasonally adjusted. While such "mixing" of data in the empirical analysis is unfortunate, the alternatives are limited, since the seasonally unadjusted CPI is the variable of interest, and unadjusted data are not available on all of the CPI's potential determinants. See Ericsson, Hendry and Tran (1994) and the papers in Hylleberg (1992) for possible implications of using seasonally adjusted data in economic modelling.

\section{INTEGRATION AND COINTEGRATION}

This section presents unit root tests for the variables of interest (Section 4.1). Then, Johansen's maximum likelihood procedure is applied to test for cointegration among the CPI, unit labour costs, import prices, and petrol prices (Section 4.2). Long-run price homogeneity and the adjustment mechanism are examined in the Johansen framework; and the estimated long-run elasticities are contrasted with those obtained by the Engle-Granger approach.

\subsection{Integration}

Before modelling the CPI, it is useful to determine the orders of integration for the variables considered. Table 1 lists fourth-order augmented DickeyFuller (1981) (ADF(4)) statistics for the CPI, unit labour costs, import prices, and petrol prices. Under standard optimizing behaviour, the mark- 


\section{Table 1: \\ ADF(4) Statistics for Testing for a Unit Root in Various Time Series}

\begin{tabular}{ccccccc}
\hline & \multicolumn{7}{c}{ Variable } \\
\cline { 2 - 7 } Null Order & $p$ & $u l c$ & $i p$ & pet & $u^{s}$ & $u^{d}$ \\
\hline \multirow{2}{*}{$\mathrm{I}(1)$} & 0.91 & -0.93 & -1.25 & -2.20 & -2.24 & -3.18 \\
& $(0.02)$ & $(-0.05)$ & $(-0.06)$ & $(-0.12)$ & $(-0.18)$ & $(-0.40)$ \\
$\mathrm{I}(2)$ & -3.01 & $-3.77^{*}$ & -2.55 & $-4.04^{*}$ & -2.86 & -3.38 \\
& $(-0.44)$ & $(-1.00)$ & $(-0.68)$ & $(-1.56)$ & $(-0.95)$ & $(-1.05)$ \\
$\mathrm{I}(3)$ & $-4.91^{* *}$ & $-5.35^{* *}$ & $-5.76^{* *}$ & $-6.59^{* *}$ & $-5.79^{* *}$ & $-5.66^{*}$ \\
& $(-2.15)$ & $(-2.95)$ & $(-3.27)$ & $(-4.41)$ & $(-3.82)$ & $(-3.24)$ \\
\hline
\end{tabular}

Notes

1. For a variable $x$, the augmented Dickey-Fuller (1981) statistic $\operatorname{ADF}(k)$ is the $t$ ratio on $\pi$ from the regression:

$$
\Delta x_{t}=\pi x_{t-1}+\sum_{i=1}^{k} \theta_{i} \Delta x_{t-i}+\psi_{0}+\sum_{i=1}^{3} \psi_{i} S_{i t}+\psi_{4} t+e_{t},
$$

where $k$ is the number of lags on the dependent variable, $\psi_{0}$ is a constant term, the $S_{i t}$ are centered seasonal dummies, and $t$ is a trend. For a given variable and null order of $\mathrm{I}(1)$, two values are reported: the fourth-order $(k=4)$ augmented Dickey-Fuller statistic ADF(4), and (in parentheses) the estimated coefficient on the lagged variable $x_{t-1}$. That coefficient should be zero under the null hypothesis that $x$ is $\mathrm{I}(1)$. For a null order of $\mathrm{I}(2)$ (I(3)), the same pairs of values are reported, but from regressions where $\Delta x\left(\Delta^{2} x\right)$ replaces $x$ in the equation above. Thus, these $\mathrm{ADF}(4)$ statistics are testing a null hypothesis of a unit root in $\Delta x\left(\Delta^{2} x\right)$ against an alternative of a stationary root in $\Delta x\left(\Delta^{2} x\right)$.

2. The sample is 1978(2)-1993(3) for all but the last two series, which use 1979(2)1993(3).

3. Here and elsewhere in this paper, asterisks $*$ and $* *$ denote rejection at the $5 \%$ and $1 \%$ critical values. The critical values for this table are calculated from MacKinnon (1991). 
up itself should be stationary, so Table 1 also includes two constructed mark-ups, $u^{s}$ and $u^{d}$, which are derived from (18) and (19) below. The deviation from unity of the estimated largest root appears in parentheses below each Dickey-Fuller statistic: this deviation should be approximately zero if the series has a unit root. Unit root tests are given for the original variables (all in logs), for their changes, and for the changes of the changes. This permits testing whether a given series is $\mathrm{I}(0), \mathrm{I}(1), \mathrm{I}(2)$, or $\mathrm{I}(3)$, albeit in a pairwise fashion for adjacent orders of integration. ${ }^{5}$

Empirically, all variables appear to be integrated of order two or lower. Unit labour costs and petrol prices appear to be I(1), whereas the CPI and import prices appear to be I(2) if inferences are made on the Dickey-Fuller statistics alone. However, the estimated roots for $\Delta p$ and $\Delta i p$ are 0.56 $(=1-0.44)$ and $0.32(=1-0.68)$ respectively, which numerically are much less than unity. Thus, all four price series are treated below as if they are I(1), while recognizing that some caveats may apply. Specifically, it may be valuable to investigate the cointegration properties of the series, assuming that they may be I(2) (see Johansen (1992b, 1992c)), but doing so is beyond the scope of this paper.

\subsection{Cointegration}

Cointegration analysis helps clarify the long-run relationships between integrated variables. Johansen's $(1988,1991)$ procedure is maximum likelihood for finite-order vector autoregressions (VARs) and is easily calculated for such systems, so it is used here. Empirically, the lag order of the VAR is not known a priori, so some testing of lag order may be fruitful in order to ensure reasonable power of the Johansen procedure. Beginning with a fourth-order VAR in $p$, ulc, ip, and pet that includes a constant term and seasonal dummies, Table A1 in Appendix 2 shows that it is statistically acceptable to simplify to a first-order VAR.

Table 2 reports the standard statistics and estimates for Johansen's procedure applied to this first-order VAR. The maximal eigenvalue and trace eigenvalue statistics $\left(\lambda_{\max }\right.$ and $\lambda_{\text {trace }}$ ) strongly reject the null of no cointegration in favour of at least one cointegrating relationship, and little

5 For $k \geq 0$, the notation $\mathrm{I}(k)$ indicates that a variable must be differenced $k$ times to make it stationary. That is, if $x_{t}$ is $\mathrm{I}(k)$, then $\Delta^{k} x_{t}$ is $\mathrm{I}(0)$. 
Table 2: A Cointegration Analysis of the Australian Price Data

\begin{tabular}{|c|c|c|c|c|c|}
\hline $\begin{array}{l}\text { Eigenvalue } \\
\text { Null hypothesis }\end{array}$ & $\begin{array}{l}0.705 \\
r=0\end{array}$ & $\begin{array}{l}0.138 \\
r \leq 1\end{array}$ & $\begin{array}{l}0.125 \\
r \leq 2\end{array}$ & $\begin{array}{l}0.058 \\
r \leq 3\end{array}$ & \\
\hline $\begin{array}{l}\lambda_{\max } \\
\lambda_{\max }^{a} \\
95 \% \text { critical value }\end{array}$ & $\begin{array}{l}79.4^{* *} \\
74.6^{* *} \\
27.1\end{array}$ & $\begin{array}{r}9.7 \\
9.1 \\
21.0\end{array}$ & $\begin{array}{r}8.7 \\
8.1 \\
14.1\end{array}$ & $\begin{array}{l}3.9^{*} \\
3.6 \\
3.8\end{array}$ & \\
\hline $\begin{array}{l}\lambda_{\text {trace }} \\
\lambda_{\text {trace }}^{a} \\
95 \% \text { critical value }\end{array}$ & $\begin{array}{l}101.7^{* *} \\
95.4^{* *} \\
47.2\end{array}$ & $\begin{array}{l}22.2 \\
20.8 \\
29.7\end{array}$ & $\begin{array}{l}12.6 \\
11.8 \\
15.4\end{array}$ & $\begin{array}{l}3.9^{*} \\
3.6 \\
3.8\end{array}$ & \\
\hline Variable & $\begin{array}{c}\text { Standar } \\
p \\
1 \\
-0.830 \\
-2.578 \\
-2.603\end{array}$ & $\begin{array}{c}\text { lized eig } \\
\text { ulc } \\
-0.495 \\
1 \\
1.538 \\
4.835\end{array}$ & $\begin{array}{c}\text { nvectors } \\
i p \\
-0.468 \\
0.242 \\
1 \\
-3.727\end{array}$ & $\begin{array}{c}\text { pet } \\
-0.066 \\
-0.206 \\
0.575 \\
1\end{array}$ & \\
\hline $\begin{array}{l}p \\
u l c \\
\text { ip } \\
\text { pet }\end{array}$ & $\begin{array}{l}\text { andardized } \\
-0.100 \\
-0.061 \\
-0.075 \\
-0.096\end{array}$ & $\begin{array}{c}\text { adjustm } \\
-0.008 \\
-0.201 \\
-0.011 \\
0.156\end{array}$ & $\begin{array}{l}\text { t coeffici } \\
-0.004 \\
-0.016 \\
-0.010 \\
-0.140\end{array}$ & $\begin{array}{r}\text { ents } \alpha \\
0.000 \\
-0.002 \\
0.017 \\
0.002\end{array}$ & \\
\hline $\begin{array}{l}\text { Variable } \\
\chi^{2}(\cdot) \\
p \text {-value }\end{array}$ & $\begin{array}{l}\text { Weak ex } \\
p \\
63.1^{* *} \\
{[0.00]}\end{array}$ & $\begin{array}{c}\text { geneity } \\
\text { ulc } \\
1.89 \\
{[0.17]}\end{array}$ & $\begin{array}{c}\text { est statisti } \\
\quad i p \\
1.34 \\
{[0.25]}\end{array}$ & $\begin{array}{c}\text { pet } \\
0.43 \\
{[0.51]}\end{array}$ & $\begin{array}{c}\{u l c, i p, p e t\} \\
3.45 \\
{[0.33]}\end{array}$ \\
\hline $\begin{array}{l}\text { Variable } \\
\chi^{2}(3)\end{array}$ & \multicolumn{4}{|c|}{ Multivariate statistics for testing stationarity } & \\
\hline $\begin{array}{l}\text { Variable } \\
\chi^{2}(1)\end{array}$ & $\begin{array}{l}\text { or testing t } \\
p \\
25.4^{* *}\end{array}$ & $\begin{array}{l}\text { ne signif } \\
\text { ulc } \\
7.3^{* *}\end{array}$ & $\begin{array}{l}\text { ance of a } \\
\quad \text { ip } \\
29.2^{* *}\end{array}$ & $\begin{array}{l}\text { given var } \\
\text { pet } \\
2.8\end{array}$ & able \\
\hline
\end{tabular}

Notes

1. The vector autoregression includes a single lag on each variable ( $p, u l c, i p$, pet), a constant term, and quarterly dummies. The estimation period is 1977(3)-1993(3).

2. The statistics $\lambda_{\max }$ and $\lambda_{\text {trace }}$ are Johansen's maximal eigenvalue and trace eigenvalue statistics for testing cointegration. The null hypothesis is in terms of the cointegration rank $r$ and, e.g., rejection of $r=0$ is evidence in favour of at least one cointegrating vector. The statistics $\lambda_{\max }^{a}$ and $\lambda_{\text {trace }}^{a}$ are the same as $\lambda_{\max }$ and $\lambda_{\text {trace}}$, but with a degrees-of-freedom adjustment. The critical values are taken from Osterwald-Lenum (1992, Table 1).

3. The weak exogeneity test statistics are evaluated under the assumption that $r=1$ and so are asymptotically distributed as $\chi^{2}(1)\left(\chi^{2}(3)\right.$ for the joint test of $\{u l c, i p, p e t\})$ if weak exogeneity of the specified variable(s) for the cointegrating vector is valid. 
evidence exists for more than one. Parallel statistics with a degrees-offreedom adjustment ( $\lambda_{\text {max }}^{a}$ and $\lambda_{\text {trace }}^{a}$ ) give a similar picture, reflecting one very large eigenvalue (0.705) and three small eigenvalues.

Table 2 also reports the standardized eigenvectors and adjustment coefficients, denoted $\beta^{\prime}$ and $\alpha$ in a common notation. The first row of $\beta^{\prime}$ is the estimated cointegrating vector, which can be written in the form of (2):

$$
p=\ln (\widehat{\mu})+0.495 u l c+0.468 i p+0.066 p e t
$$

where a circumflex - denotes an estimated or fitted value. All coefficients have their anticipated signs. Numerically, the coefficients on $u l c$ and ip are approximately equal in value, reflecting the opposite and matching fluctuations of their real values in Figure 8. The sum of coefficients in (6) is close to unity (1.029), and statistically the restriction of long-run unit homogeneity cannot be rejected: $\chi^{2}(1)=0.61[0.44]$; see Johansen and Juselius (1990) for the form of the test. The asymptotic null distribution is denoted by $\chi^{2}(\cdot)$ with degrees of freedom in parentheses, and the asymptotic $p$-value is in square brackets. With long-run unit homogeneity imposed, (6) becomes:

$$
p=\ln (\widehat{\mu})+0.426 u l c+0.481 i p+0.093 p e t .
$$

Thus, the unit labour costs and import prices each have long-run elasticities of slightly less than one half, with petrol prices making up the remainder of about one tenth. The economic reasonability of these estimates is discussed in Section 6.

The coefficients in the first column of $\alpha$ measure the feedback effect of the (lagged) disequilibrium in the cointegrating relation onto the variables in the vector autoregression. Specifically, -0.100 is the estimated feedback coefficient for the CPI equation. The negative coefficient implies that an "excess" mark-up induces a lower CPI inflation rate. The coefficient's numerical value entails gradual adjustment to remaining disequilibrium and so substantial smoothing of unit labour costs, import prices, and petrol prices in obtaining the CPI.

The next row of Table 2 reports values of the statistic for testing weak 
exogeneity of a given variable for the cointegrating vector. Equivalently, the statistic tests whether or not the corresponding row of $\alpha$ is zero; see Johansen (1992a, 1992c). If it is zero, disequilibrium in the cointegrating relationship does not feed back onto that variable. Individually and jointly, unit labour costs, import prices, and petrol prices are weakly exogenous. Imposing weak exogeneity of unit labour costs, import prices, and petrol prices jointly with long-run homogeneity also is not rejected: $\chi^{2}(4)=4.99$ [0.29]. The corresponding estimate of the cointegrating vector is:

$$
p=\ln (\widehat{\mu})+0.419 u l c+0.487 i p+0.094 p e t
$$

and the feedback coefficient in the equation for $p$ is -0.081 . These estimates are virtually unchanged numerically from the unrestricted ones (Table 2) or from those obtained by imposing subsets of the hypotheses (e.g., as in (7)). The similarity of coefficient estimates across the various restrictions points to the robustness of the results and is partial evidence in favour of those restrictions. Weak exogeneity implies that the cointegrating vector and the feedback coefficients enter only the CPI equation, so inferences about those parameters can be conducted from a conditional model of the CPI alone without loss of information. Thus, weak exogeneity permits a much simpler modelling strategy, namely, a single equation analysis rather than a system one. Given the empirically acceptable restriction of weak exogeneity, Sections 5-7 pursue a single equation analysis of the CPI.

For comparison with (6), (7), and (8), Engle and Granger's (1987) test of cointegration obtains:

$$
\begin{aligned}
& \widehat{p_{t}}=-0.834+0.934 u l c_{t}+0.300 i p_{t}-\text { 0.060pet }_{t} \\
& T=65[1977(3)-1993(3)] \quad \mathrm{R}^{2}=0.9947 \quad \hat{\sigma}=2.639 \% \\
& d w=0.40 \quad A D F(0)=-2.56 \quad A D F(1)=-2.45 .
\end{aligned}
$$

$T, \mathbf{R}^{2}, \hat{\sigma}$, and $d w$ are the sample size of the estimation period, the squared multiple correlation coefficient, the estimated equation standard error, and the Durbin-Watson statistic respectively; the coefficients are estimated by least squares; and the ADF statistics are calculated on the residuals from 
that static regression, which includes seasonal dummies (not reported in (9)). Neither of the ADF statistics is significant at MacKinnon's (1991) $90 \%$ critical level, paralleling the apparent unit roots in Table 1 for the two constructed mark-ups, $u^{s}$ and $u^{d}$. Even if cointegration is assumed, the coefficient on pet in (9) has the wrong sign, and long-run homogeneity does not appear to be satisfied, although formal testing is difficult, given the complicated distribution of the coefficient estimates. These discrepancies between the Johansen and Engle-Granger procedures may arise because the procedures treat dynamics differently. Kremers, Ericsson and Dolado (1992) show analytically that the ADF test has low power relative to Johansen and error correction-based procedures unless the dynamics of the process satisfy a "common factor restriction". That restriction is rejected for the error correction model developed in the next section. ${ }^{6}$

The penultimate row of Table 2 reports values of a multivariate statistic for testing the stationarity of a given variable. Specifically, this statistic tests the restriction that the cointegrating vector contains all zeros except for a unity corresponding to the designated variable, where the test is conditional on there being one cointegrating vector. For instance, the null hypothesis of a stationary CPI implies that the cointegrating vector is $\left(\begin{array}{llll}1 & 0 & 0 & 0\end{array}\right)^{\prime}$. Empirically, all the stationarity tests reject with $p$-values less than $0.01 \%$. By being multivariate, these statistics may have higher finite sample power than their univariate counterparts. Also, the null hypothesis is the stationarity of a given variable rather than the nonstationarity thereof, and stationarity may be a more appealing null hypothesis. That said, these rejections of stationarity are in line with the inability in Table 1 to reject the null hypothesis of a unit root in each of $p$, ulc, ip, and pet.

The final row of Table 2 reports chi-squared statistics for testing the significance of individual variables in the cointegrating vector. Each variable is significant except for petrol prices. The latter is retained in the single equation analysis below and appears to be statistically significant, perhaps

6 Kremers, Ericsson and Dolado (1992), de Brouwer, Ng and Subbaraman (1993), and Kamin and Ericsson (1993) find that invalid common factor restrictions markedly reduce the empirical power of the Engle-Granger procedure for detecting cointegration in money demand equations. Banerjee, Dolado, Hendry and Smith (1986) show that the static estimates may have large finite sample biases, which would explain the discrepancies between (9) and (6)-(8); see also Banerjee, Dolado, Galbraith and Hendry (1993). 
from the additional restrictions on dynamics, including weak exogeneity.

\section{A SINGLE EQUATION MODEL OF INFLATION}

The following three sections present estimation results for a single-equation error correction model of inflation. To start, analytical relationships between autoregressive distributed lag models (ADLs), error correction models (ECMs), and the long-run solution (2) are discussed (Section 5.1). An estimated long-run solution is obtained from an autoregressive distributed lag of the CPI on unit labour costs, import prices, petrol prices, and an output gap; and a parsimonious ECM is derived from that autoregressive distributed lag (Section 5.2). The ECM has sensible economic and statistical properties (Section 6), it encompasses existing models (Section 7.1), and it may be useful in forecasting (Section 7.2). Readers familiar with ECMs and autoregressive distributed lags may skip directly to Section 5.2.

\subsection{Autoregressive Distributed Lags, ECMs, and Long-Run Solutions}

With the choice of variables and lag length in the vector autoregression above, a fourth-order autoregressive distributed lag model in $p$, ulc, ip, and pet is a natural starting point for single equation modelling. This regression is modified in two ways. First, the output gap $y^{\text {res }}$ is included to reflect how the mark-up $\mu-1$ may vary over the cycle. Second, a dummy $D$ is included for an increase in indirect taxes in December 1978. ${ }^{7}$ Thus, the fourth-order $\mathrm{ADL}$ of the underlying $\mathrm{CPI}$ is:

$$
\begin{aligned}
p_{t}= & a_{0}+\sum_{i=1}^{4} a_{1 i} p_{t-i}+\sum_{i=0}^{4} a_{2 i} u l c_{t-i}+\sum_{i=0}^{4} a_{3 i} i p_{t-i}+\sum_{i=0}^{4} a_{4 i} p t_{t-i} \\
& +\sum_{i=0}^{4} a_{5 i} y_{t-i}^{r e s}+\sum_{i=1}^{3} a_{6 i} S_{i t}+a_{7} D_{t}+v_{t},
\end{aligned}
$$

where $v_{t}$ is the error term. As with the cointegration analysis, a constant

7 While the output gap and the dummy $D_{t}$ may capture economically and statistically important behaviour in prices, their effects are viewed as short run and so are not included in the cointegration analysis above. If included, the cointegration results are virtually unchanged. 
term and seasonal dummies are included: $S_{i t}$ denotes the centered (zero mean) seasonal dummy for the $i$ th quarter.

Equation (10) may be reparameterized without loss of generality as an unrestricted ECM by adding and subtracting lags of the variables:

$$
\begin{aligned}
\Delta p_{t}= & a_{0}+\sum_{i=1}^{3} b_{1 i} \Delta p_{t-i}+\sum_{i=0}^{3} b_{2 i} \Delta u l c_{t-i}+\sum_{i=0}^{3} b_{3 i} \Delta i p_{t-i} \\
& +\sum_{i=0}^{3} b_{4 i} \Delta p e t_{t-i}+\sum_{i=0}^{3} b_{5 i} \Delta y_{t-i}^{r e s} \\
& +c_{1} p_{t-1}+c_{2} u l c_{t-1}+c_{3} i p_{t-1}+c_{4} \text { pet }_{t-1}+c_{5} y_{t-1}^{r e s} \\
& +\sum_{i=1}^{3} a_{6 i} S_{i t}+a_{7} D_{t}+v_{t} .
\end{aligned}
$$

With minor algebraic manipulation, equation (11) may be rewritten so as to incorporate the long-run solution (2) directly.

$$
\begin{aligned}
\Delta p_{t}= & a_{0}+\sum_{i=1}^{3} b_{1 i} \Delta p_{t-i}+\sum_{i=0}^{3} b_{2 i} \Delta u l c_{t-i}+\sum_{i=0}^{3} b_{3 i} \Delta i p_{t-i} \\
& +\sum_{i=0}^{3} b_{4 i} \Delta p e t_{t-i}+\sum_{i=0}^{3} b_{5 i} \Delta y_{t-i}^{r e s} \\
& +c_{1}(p-\gamma u l c-\delta i p-\kappa p e t)_{t-1}+c_{5} y_{t-1}^{r e s} \\
& +\sum_{i=1}^{3} a_{6 i} S_{i t}+a_{7} D_{t}+v_{t} .
\end{aligned}
$$

Specifically, $c_{1}$ (with $c_{1}<0$ for dynamic stability) is the feedback coefficient for the measure of disequilibrium,

$$
(p-\gamma u l c-\delta i p-\kappa p e t)_{t-1}
$$

which is the empirical mark-up in the previous period. The coefficients $\gamma$, 
$\delta$, and $\kappa$ are $-c_{2} / c_{1},-c_{3} / c_{1}$, and $-c_{4} / c_{1}$, which are the long-run elasticities in (2).

Some straightforward algebraic manipulation of (11) obtains various equilibrium solutions, including the solution (2). Extensive discussions of the relationship between the ECM and its long-run solutions appear in Davidson, Hendry, Srba and Yeo (1978), Hendry, Pagan and Sargan (1984), and Hendry (1995). Under a non-stochastic static-state equilibrium, the output gap, all growth rates, and the error term $v_{t}$ are zero in (11); time subscripts are dropped; and the seasonals and dummy can be ignored. That leaves (11) with the constant $a_{0}$ and the levels $p, u l c, i p$, and pet. Moving $p$ to the left-hand side and renormalizing, (11) solves for (2):

$$
p^{s}=-\left(\frac{a_{0}}{c_{1}}\right)-\left(\frac{c_{2}}{c_{1}}\right) u l c-\left(\frac{c_{3}}{c_{1}}\right) i p-\left(\frac{c_{4}}{c_{1}}\right) \text { pet. }
$$

The superscript $s$ in $p^{s}$ indicates that (14) is the static equilibrium. The constant term $-a_{0} / c_{1}$ in (14) is equivalent to $\ln (\mu)$ in (2), where the latter is the logarithmic approximation to the mark-up $\mu-1$. Thus, the error correction model (11) solves for the long-run solution (2) when evaluated under the non-stochastic static-state assumptions associated with (2).

Equation (14) is the static equilibrium of the ECM (11), where static means assuming that all prices are constant. More generally, (11) might be evaluated under various steady-state (rather than static-state) assumptions. Under one such set of assumptions, all prices grow at some constant rate $g(\Delta p=\Delta u l c=\Delta i p=\Delta p e t=g)$ and the output gap $y^{r e s}$ is constant but possibly nonzero. That is, a nonzero inflation rate and a nonzero output gap are two simple aspects of a dynamic equilibrium. ${ }^{8}$ Solving (11) for $p$ in a similar manner to that done for (14), the resulting dynamic equilibrium price level $p^{d}$ is:

$$
p^{d}=-\left(\frac{a_{0}}{c_{1}}\right)-\left(\frac{c_{2}}{c_{1}}\right) u l c-\left(\frac{c_{3}}{c_{1}}\right) i p-\left(\frac{c_{4}}{c_{1}}\right) p e t-\phi g-\left(\frac{c_{5}}{c_{1}}\right) y^{r e s},
$$

8 Other dynamic equilibria exist, e.g., ones with nonzero growth rates in real prices such that the error correction in (12) is constant. However, the solution in (15) is the simplest of the dynamic equilbrium paths; and it has a certain economic appeal in that all real prices are assumed constant. 
where $\phi$ is a complicated function of $\left\{b_{j i}, j=1, \ldots, 4\right\}$ and $c_{1}$. Equation (15) generalizes (14) for nonzero price growth rates and a nonzero output gap. In particular, the logarithmic approximation to the mark-up is $-\left(a_{0} / c_{1}\right)-\phi g-\left(c_{5} / c_{1}\right) y^{r e s}$ rather than just $-\left(a_{0} / c_{1}\right)$ : the inflation rate and the output gap influence the mark-up, and so influence the level of the CPI relative to other prices. This formulation captures a way in which the mark-up might vary over the cycle.

For each of (14) and (15), a time series of disequilibria can be constructed by subtracting the right-hand side of the respective equation from $p$, evaluating all variables at observed values. These disequilibrium measures are denoted $u^{s}$ and $u^{d}$ respectively.

This paper presents estimates of the coefficients in (14) under different assumptions. In the VAR framework of Section 4.2, equations (6), (7), and (8) respectively assume nothing, long-run price homogeneity, and long-run price homogeneity and weak exogeneity. In the single equation framework of Sections 5.2 and 6.1 below, (16) and (18) respectively assume weak exogeneity only, and weak exogeneity, long-run price homogeneity, and a simplified lag structure. Comparison of estimates across these various equations indirectly assesses the associated assumptions themselves. Section 6.1 also reports the dynamic solution (15) and compares the static and dynamic equilibrium prices with actual prices, both directly and through the corresponding disequilibrium measures $u^{s}$ and $u^{d}$.

Equation (12) generalizes the conventional partial adjustment model by allowing separate reaction speeds to the different determinants of the CPI, reflecting potentially different costs of adjustment and of disequilibrium. Through the error correction term, (12) allows discrepancies between the log-level of the CPI and its determinants to affect future inflation, thus keeping the level of the CPI "in line" with its determinants in the long run. Economically, (12) is related to Ss-type models, with short-run factors determining CPI movements within a given price environment and longerrun factors determining the general level of prices. In particular, short-run factors affect the mark-up itself. For further details, see Nickell (1985) for an optimizing framework that results in an error correction model, and Smith (1986) for the ECM's relation to $S s$ inventory models, albeit in the context of money demand. 
The ECM (12) is a remarkably general model. In particular, it contains both static levels models and pure difference models of inflation as special (and testable) cases. The ECM's relation to models in levels follows from the equivalence of (12) with the ADL in (10), and restricting the ADL such that all $a_{j i}$ are zero for $j=1, \ldots, 5$ and $i>0$. The ECM's relation to models in differences follows directly from (12) with $c_{1}$ (and possibly $c_{5}$ ) set to zero. Thus, models in differences contain no information about the long run, i.e., on the levels. As is readily apparent from the empirical ECM (17) developed in Section 5.2, neither static models nor models in differences alone are empirically satisfactory. Section 7.1 further discusses these issues in the context of encompassing.

Ostensibly, equation (12) explains inflation. It also determines the price level through its relationship with (10), provided $c_{1} \neq 0$. For detailed discussion on the algebra of ECMs, see Hendry, Pagan and Sargan (1984), Ericsson, Campos and Tran (1990), and Hendry (1995).

\subsection{General to Specific Modelling}

This subsection simplifies the fourth-order ADL to a parsimonious ECM. Sections 6 and 7 examine the estimated model's economic and statistical properties in greater detail.

Most of the individual coefficients in the fourth-order ADL (10) are imprecisely estimated and are of little interest in themselves. However, the long-run solution of the ADL is of interest, and its coefficients are welldetermined:

$$
p=\underset{(0.274)}{-0.094}+\underset{(0.161)}{0.516} u l c+\underset{(0.078)}{0.463} \mathrm{ip}+\underset{(0.056)}{0.055} \mathrm{pet}
$$

where estimated standard errors are in parentheses $(\cdot)$. Equation (16) corresponds to (2) and (14). The estimates in (16) are very close to those obtained by Johansen's analysis of the VAR. Simplification of the fourthorder ADL to a first-order ADL is statistically acceptable, and achieves a virtually identical long-run solution with somewhat smaller standard errors, paralleling the system result that only first lags matter.

When the fourth-order ADL is transformed to the unrestricted ECM rep- 
resentation (11), many of the coefficients are both economically and statistically insignificant; see Table A2 in Appendix 2. For instance, no lags (other than lagged log-levels) appear important. These and other restrictions described in Appendix 2 provide a natural path for the simplification of (11) to the following highly parsimonious, economically interpretable, and statistically acceptable ECM.

$$
\begin{aligned}
& \widehat{\Delta p}_{t}=+\underset{(0.0060)}{0.0141} \Delta \text { pet }_{t}+\underset{(0.0113)}{0.0763} y_{t-1}^{\text {res }} \\
& -\underset{(0.0069)}{0.0891}(p-\underset{(0.056)}{0.465} \text { ulc }-\underset{(0.050)}{0.443} \mathrm{ip}-\underset{(0.026)}{0.092} \mathrm{pet})_{t-1} \\
& +0.0096 D_{t}+0.00749 \\
& \text { (0.0028) (0.00072) } \\
& -\underset{(0.0009)}{0.0017} S_{1 t}-\underset{(0.0009)}{0.0009} S_{2 t}-\underset{(0.0009)}{0.0021} S_{3 t} \\
& T=65[1977(3)-1993(3)] \quad R^{2}=0.87 \quad \hat{\sigma}=0.251 \% \\
& A R: F(5,50)=0.59 \quad d w=1.98 \quad A R C H: F(4,47)=0.85 \\
& \text { Normality }: \chi^{2}(2)=2.24 \quad R E S E T: F(1,54)=0.22 \\
& \text { Hetero }: F(14,40)=0.99 \quad \text { Inn }: F(19,36)=0.66 \\
& L M_{p}: F(1,54)=0.09 \text {. }
\end{aligned}
$$

In (17), just three economic variables affect CPI inflation: the current change in petrol prices, the previous quarter's output gap, and the previous quarter's mark-up. These variables are all statistically significant, particularly the latter two. The output gap and the change in petrol prices have positive effects; and the mark-up has a negative effect, as required for dynamic stability of the equation. Indirect taxes (through $D_{t}$ ) and seasonality also affect inflation. The coefficients in (17) are consistent with the mark-up model (2), where the mark-up itself varies with the output gap. Section 6 considers the dynamic and long-run implications of the variables in (17) at greater length, showing how to obtain those implications from the analytics of Section 5.1.

Equation (17) lists diagnostic statistics for testing against various alternative hypotheses: residual autocorrelation ( $A R$ and $d w)$, autoregressive conditional heteroscedasticity $(A R C H)$, skewness and excess kurtosis 
(Normality), RESET (RESET), heteroscedasticity (Hetero), and noninnovation errors relative to the fourth-order ADL (Inn). ${ }^{9}$ The null distribution is designated by $\chi^{2}(\cdot)$ or $F(\cdot, \cdot)$, the degrees of freedom fill the parentheses, and (for $A R$ and $A R C H$ ) the lag order is the first degree of freedom. Statistically, the ECM appears well-specified, with no rejections from the tests available. Also, the imposed restriction of long-run price homogeneity is not rejected by the appropriate Lagrange multiplier statistic $\left(L M_{p}\right)$.

For convenience, the ECM (17) will be called the preferred equation. Appendix 3 develops an alternative ECM, which contains an additional term for the dynamic effects of the business cycle on inflation.

\section{THE MODEL'S PROPERTIES}

This section considers the economic interpretation and statistical properties of the ECM in (17). Sections 6.1 and 6.2 focus on the long-run and dynamic properties of the model, Section 6.3 demonstrates the model's empirical constancy, and Section 6.4 offers a few caveats.

\subsection{Long-Run Properties of the Model}

The long-run properties of an error correction model can be characterized by its static and dynamic solutions $\left(p^{s}\right.$ and $\left.p^{d}\right)$, and by the implied disequilibria from those solutions $\left(u^{s}\right.$ and $\left.u^{d}\right)$. This subsection analyzes those solutions and associated disequilibria, both numerically and graphically.

Equation (17) embeds the mark-up model (2) in its static long-run solution $p^{s}$, which is:

$$
p^{s}=0.084+0.465 u l c+0.443 i p+0.092 p e t
$$

corresponding to (14). The dynamic equilibrium solution $p^{d}$ is:

9 For references on the test statistics, see Durbin and Watson (1950, 1951), Box and Pierce (1970), Godfrey (1978), and Harvey (1981, p. 173); Engle (1982); Jarque and Bera (1980) and Doornik and Hansen (1994); Ramsey (1969); White (1980, p. 825) and Nicholls and Pagan (1983); and Hendry (1995) respectively. 


$$
\begin{aligned}
p^{d}= & 0.084+0.465 u l c+0.443 i p+0.092 p e t \\
& -11.1 g+0.86 y^{\text {res }},
\end{aligned}
$$

as derived from (15). Long-run homogeneity is statistically acceptable and is imposed in (18) and (19). The estimates of the long-run solution in (18) from the ECM are numerically close to the system estimates of the cointegrating vector in (6), (7), and (8), and to the single equation estimates in (16) from the unrestricted ADL. This robustness of results provides some indirect evidence in favour of the assumptions imbedded in the final ECM relative to the unrestricted VAR. The tests above of long-run homogeneity, weak exogeneity, and innovation errors provide the direct evidence.

Consumer prices, their static equilibrium, and their dynamic equilibrium are shown in Figure 10. To calculate $p^{s}$ and $p^{d}$ for the figure, currentdated variables are used on the right-hand side of (18) and (19). Further, $g$ must be specified for (19); and the average $\sum_{i=0}^{3} \Delta p_{t-i} / 4$ is used so as to smooth the relatively erratic inflation series. Seasonal dummies as well as the constant term are included in calculating both $p^{s}$ and $p^{d}$. Actual prices and the dynamic equilibrium path are quite similar: deviations between them $\left(u^{d}\right)$ are typically only a few per cent, with those deviations lasting a year or two at a time; see Figure 11. Recently, actual prices have been particularly close to the dynamic equilibrium path. By comparison, the static equilibrium path consistently lies above actual prices, often by $20 \%$ to $30 \%$. This discrepancy $\left(u^{s}\right)$ primarily reflects omission of the term $-\phi g$ from the calculation of $p^{s}$ in (14). The estimate of $-\phi$ in (19) is large and negative $(-11.1)$, and the quarterly inflation rate often is $2 \%$ to $3 \%$, implying discrepancies of the magnitude observed and contrasting with the zero inflation rate assumed in solving for $p^{s}$.

The importance of the growth rate $g$ in the dynamic equilibrium solution has different interpretations. Most straightforwardly, $\ln (\mu)$, the mark-up from (2), depends negatively on $g$. As $g$ declines in the late 1980s and the early 1990s, the mark-up increases, as seen from the plot of $p-p^{s}$ in Figure 11. More subtly, $p$, ulc, ip, and pet might be I(2), cointegrating as in (2) to form an I(1) linear combination, which itself could cointegrate with the inflation rate (I(1) here by assumption) to form an $\mathrm{I}(0)$ combination. The dynamic equilibrium (19) would then be that $\mathrm{I}(0)$ combination. In 
Figure 10: Actual CPI $p(-)$, the static solution $p^{s}(\cdots)$, and the dynamic solution $p^{d}(--)$.

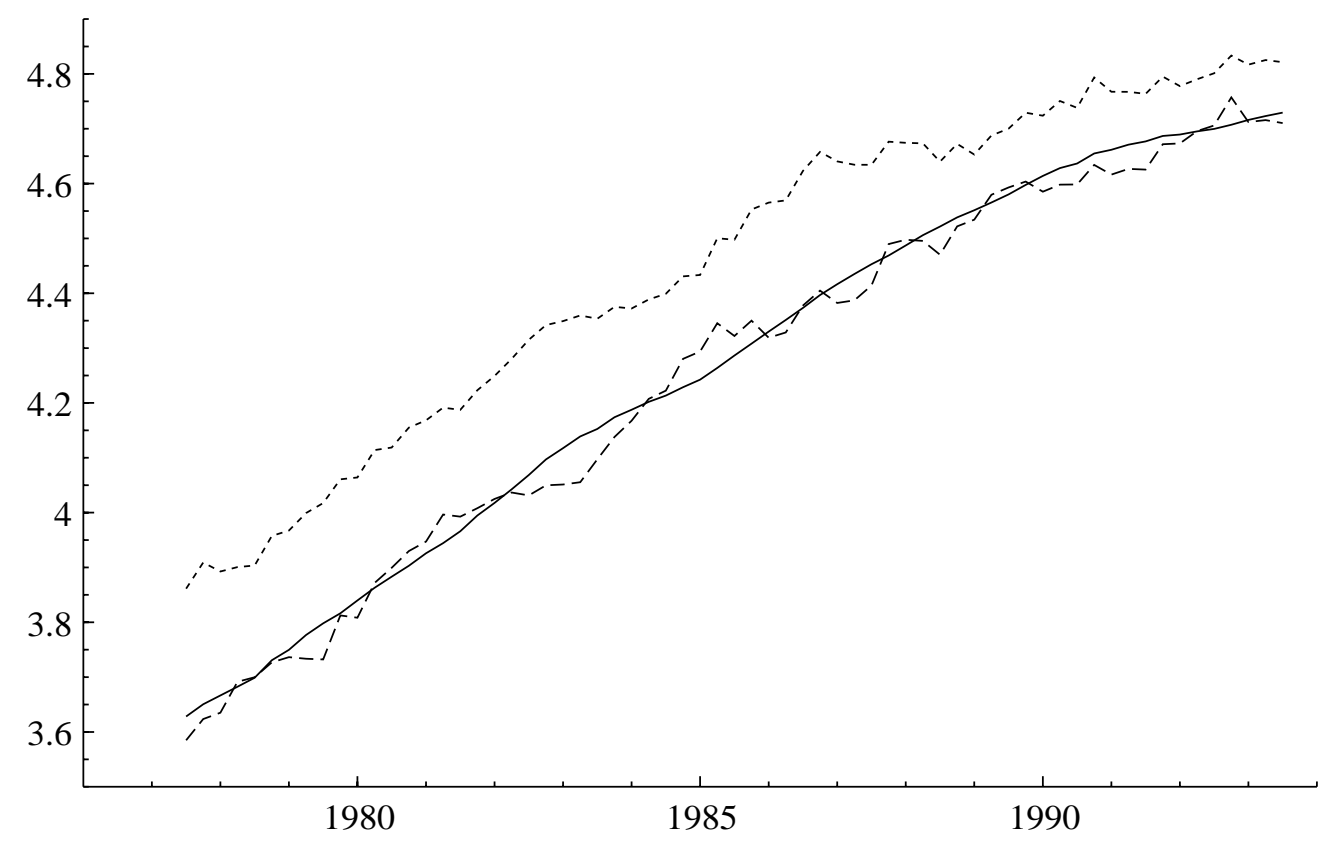

Figure 11: Deviations between the actual CPI and the static solution $p-p^{s}(\cdots)$ and between the actual CPI and the dynamic solution $p-p^{d}(--)$.

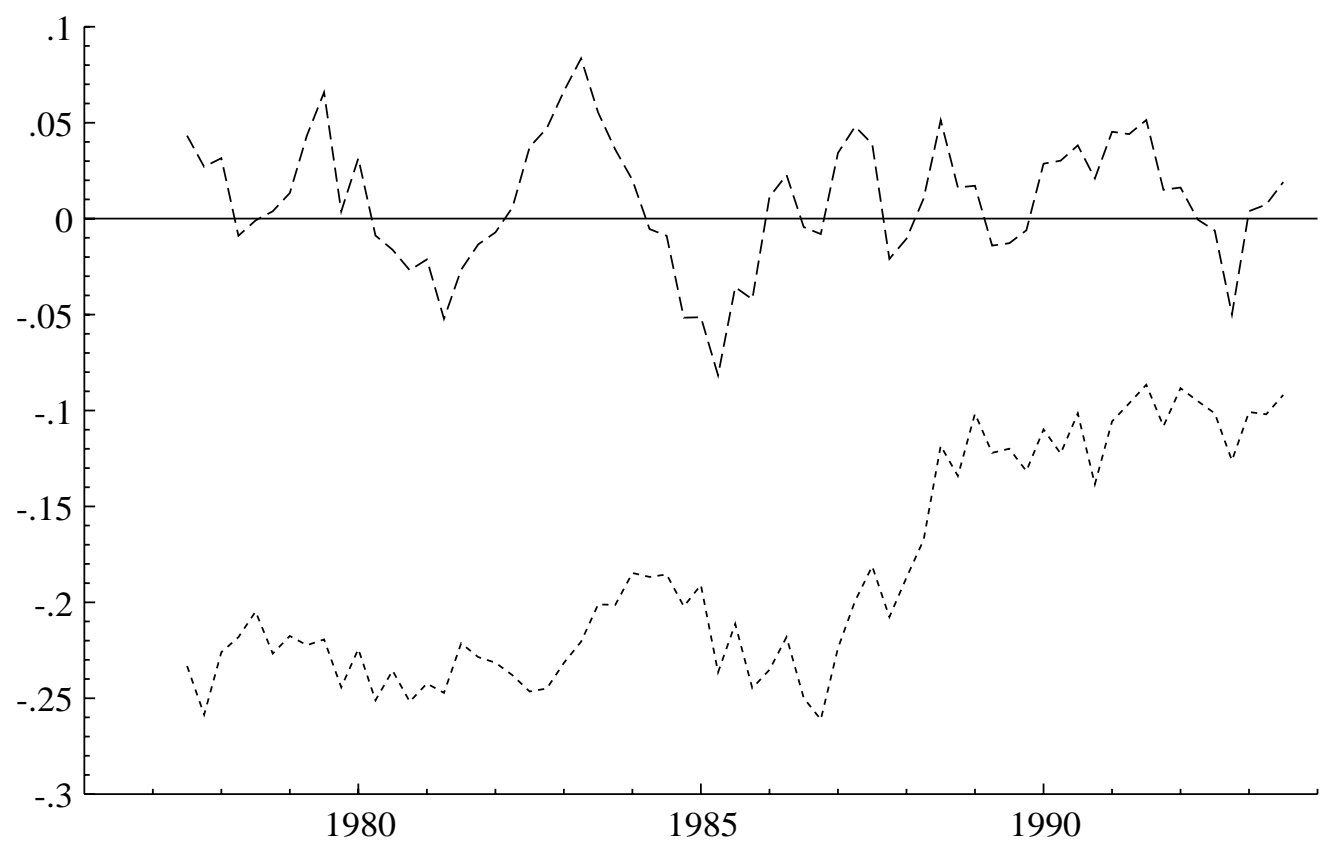


principle, $p$, ulc, ip, and pet might be I(2), although a nonstationary markup is economically unappealing. For Australia with this data, $p, u l c, i p$, and pet appear to be I(1) empirically. The ADF statistics and estimated coefficients in Table 1 and the multivariate stationarity tests in Table 2 support that these variables are I(1). Also, Johansen's (1992c) analysis implies that variables are at most I(1) if, as in the VAR considered above, their vector autoregression is first order with a single cointegrating vector, weak exogeneity for that cointegrating vector, and a nonzero cointegrating coefficient on the endogenous variable. As an intermediate alternative, $p$, ulc, ip, and pet might be I(1) and cointegrated, but with their mean growth rates shifting down in the latter part of the sample. If the mark-up depends upon $g$, then the mark-up might appear nonstationary because of that shift in $g$; see Campos, Ericsson and Hendry (1996).

Both disequilibrium measures $u^{s}$ and $u^{d}$ are stationary series in that they correspond to the observed cointegrating vector. That said, both series appear to be nonstationary from the augmented Dickey-Fuller statistics in Table 1. This seeming contradiction is resolved by the higher power of the Johansen procedure relative to ADF statistics for detecting the stationarity of multivariate relationships. Equally, a univariate procedure such as the ADF statistic is at an inherent disadvantage when used to evaluate multivariate hypotheses such as cointegration.

The long-run coefficient estimates are plausible and sensible. Numerically, the coefficient on unit labour costs is the largest and that on fuel prices the smallest. This accords with conventional wisdom. The coefficient on import prices is perhaps a little more controversial, and is not statistically different from that on unit labour costs. Specifically, the coefficient is higher than $0.2-0.3$, which is a range quoted by some commentators and which is similar to the import propensity for all goods and services (about 0.2 ). The estimated elasticity bears on the potential inflationary impact of recent exchange rate depreciations. The Australian dollar depreciated by over 10\% between March and August in 1992 and by 5\% in May 1993. The ECM (17) indicates that the CPI eventually rises by $0.44 \%$ for every $1 \%$ permanent increase in import prices. The import elasticity in (17) may depend on the definitions of the right-hand side variables selected, and other definitions and specifications may yield different results. Still, this result is robust across the specifications considered herein. 
Several factors may account for the higher estimated import price coefficient in (17). First, many pre-existing models of the CPI were in growth rates only, so the imputed long-run elasticities were actually short-run rather than long-run. For example, estimating equation (11) as a distributed lag model with six lags but without the error correction term yields a solved import price coefficient of about 0.2. From Section 6.2 below, 0.2 is approximately the six-period cumulated response implied by (17). Second, the appropriate benchmark for the import price effect is, at a minimum, the share of importables rather than the share of imports, with the former being larger than the latter. Third, the market for exportables may be important. If the price of exportables sold in the domestic market is set at the world price (which is assumed to be given to exporters), then this creates an additional channel by which a depreciation will be inflationary. Since movements in import prices are dominated by movements in the exchange rate, an effect from the price of exportables will be picked up by the import price series. Fourth, if domestic producers and retailers price strategically or attempt to maintain some relativity to import prices, then the import price coefficient will be higher than the importables propensity. Fifth, as mentioned above, many previous models of Australian CPI were estimated in differences only, with smaller estimated "long-run" elasticities for imports. To the extent that comparisons are made, it seems plausible that those earlier results are biased downward from using differences only.

Finally, the modelled CPI is the underlying CPI, not headline CPI. The underlying CPI accounts for approximately $80 \%$ of the headline CPI. So, using equation (17), the long-run effect of a change in import prices on headline CPI is about 0.36 (or about 0.38 if the share of petrol is excluded), assuming that import prices do not influence the price of items excluded from the underlying CPI. It is also worth noting that the numbers in (17) are point estimates: plus-or-minus two standard errors on the estimated import price elasticity yields a confidence interval of 0.34 to 0.54 .

\subsection{Dynamic Properties of the Model}

Equation (17) has several implications for lags and lag distributions and for the economic interpretation of the error correction term. First, the CPI adjusts slowly to shocks, even though lag lengths in (17) are short. Representation of the ECM as an ADL helps clarify this apparent disparity, as does solving for the implied lag distributions of the estimated ECM. 
Second, the error correction term in (17) is interpretable as capturing feedbacks from the domestic labour market, the foreign goods market, and the energy market.

In (17), adjustment to disequilibrium is very gradual, even though no lags beyond the first are necessary in that equation (see Appendix 2). The explanation follows from the small coefficient on the error correction term $(-0.0891)$ and small or zero coefficients on contemporaneous variables. When rewritten as the autoregressive distributed lag representation (10), equation (17) becomes:

$$
\begin{aligned}
\widehat{p_{t}}= & +0.9109 p_{t-1}+0.0415 \text { ulc }_{t-1}+0.0394 i p_{t-1} \\
& +0.0141 \text { pet }_{t}-0.0059 \text { pet }_{t-1}+0.0763 y_{t-1}^{\text {res }},
\end{aligned}
$$

where the constant, seasonals, and dummy $D$ are omitted for simplicity of exposition. The small ECM coefficient in (17) implies a large coefficient (0.9109) on the lagged dependent variable $p_{t-1}$ in (20), generating long solved distributed lags of unit labour costs, import prices, energy prices, and the output gap.

For example, suppose import prices increase permanently by $10 \%$ in a given quarter. Current-dated import prices do not appear in (20), so the contemporaneous response of the CPI is zero. One quarter later, the CPI increases by $0.394 \%$, noting that the coefficient on $i p_{t-1}$ in (20) is 0.0394 (equivalently, $(-0.0891) \cdot(-0.443)$ from $(17))$. In each succeeding quarter, the disequilibrium is reduced by progressively smaller increments until the full $4.43 \%$ increase in the CPI is achieved, corresponding to the longrun elasticity of 0.443 for import prices. This adjustment is a drawn-out process, with just half of the adjustment completed after two years, and only three-quarters of the adjustment completed after four years. ${ }^{10}$

Thus, the model (17) incorporates the appealing idea that permanent in-

10 For a permanent change in unit labour costs, import prices, or the output gap, the proportion of adjustment through to period $n$ is $-\sum_{i=1}^{n} c_{1}\left(1+c_{1}\right)^{(i-1)}$ (or zero for $n=0$ ), where $c_{1}$ is the coefficient on the error correction term in (17). The cumulative adjustment for petrol prices is somewhat more complicated algebraically, but it is easily computed. For instance, for a $1 \%$ permanent increase in petrol prices, the contemporaneous effect on the CPI is $0.0141 \%$, which is approximately $15 \%$ $(=0.0141 / 0.092)$ of the total long-run 0.092 percentage point effect on the CPI. 
creases in costs increase the CPI in the long run whereas temporary increases in costs have small short-run effects. This is especially sensible here since unit labour costs, import prices, and petrol prices can be very volatile on a quarter-to-quarter basis. For import prices in particular, the lag structure implies that the path of the exchange rate in the few years before a depreciation mediates the proximate inflationary effect of that depreciation. The ostensible deflationary effect of the recent appreciation in the exchange rate should be viewed similarly.

Explicit lag distributions and functions thereof are easily calculated numerically. Figure 12 plots the derived normalized lag distributions for $u c_{t}$, $i p_{t}$, pet ${ }_{t}$, and $y_{t}^{\text {res }}$ from equation (17). ${ }^{11}$ Their median lags are 7, 7, 6, and 7 quarters respectively; and their mean lags are all somewhat greater than two years. Figure 13 plots the normalized cumulative lag distributions, from which the median lags are derived. Figures 12 and 13 also represent the responses of the CPI to suitably normalized temporary and permanent changes in the corresponding variables, thereby providing graphical assessment of the numerical calculations in the previous paragraphs. The relatively small error correction coefficient and contemporaneous shortrun elasticities imply substantial smoothing in the price process and major differences between short- and long-run elasticities for a given variable.

Some previous models of the Australian CPI are in differences only and require substantially longer lags. By omitting the error correction term from the autoregressive distributed lag (i.e., setting $c_{1}=0$ in (12)), the differenced variables are left to proxy the implied lagged effects graphed in Figures 12 and 13. The sums of coefficients in those differenced models have sometimes been interpreted as "long-run" elasticities. Unsurprisingly, these sums need not match the derived long-run elasticities from the error correction model, where the latter are designed to capture the level effects corresponding to the economic elasticities in (2). The autoregressive distributed lag representation (20) emphasizes that the ECM (17) determines the level $p_{t}$ and not just the growth rate $\Delta p_{t}$, even though the dependent variable in (17) is $\Delta p_{t}$. Equation (17)'s error correction term, which is in $(\log )$ levels, is the explanation. Equation (20) also shows that short lags on variables in a error correction model can be consistent with a long and

11 The normalized distributional properties for $u l c_{t}, i p_{t}$, and $y_{t}^{r e s}$ are identical because each variable enters (17) at one and the same lag (the first). 
Figure 12: The normalized lag distributions for $u l c_{t}, i p_{t}$, and $y_{t}^{r e s}(-)$ and for pet $_{t}(\cdots)$.

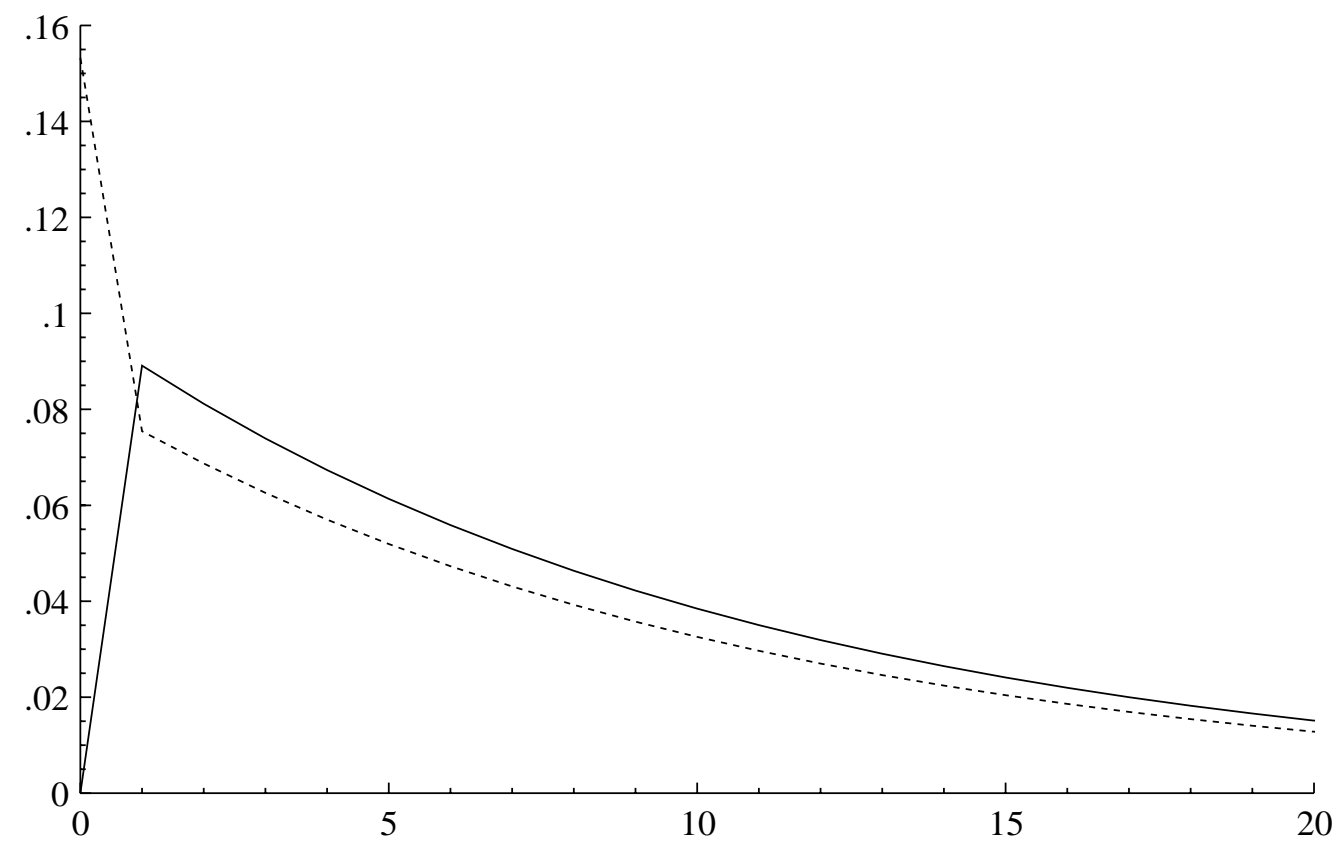

Figure 13: The normalized cumulative lag distributions for $u c_{t}$, $i p_{t}$, and $y_{t}^{\text {res }}\left(\right.$ (一) and for pet $_{t}(\cdots)$.

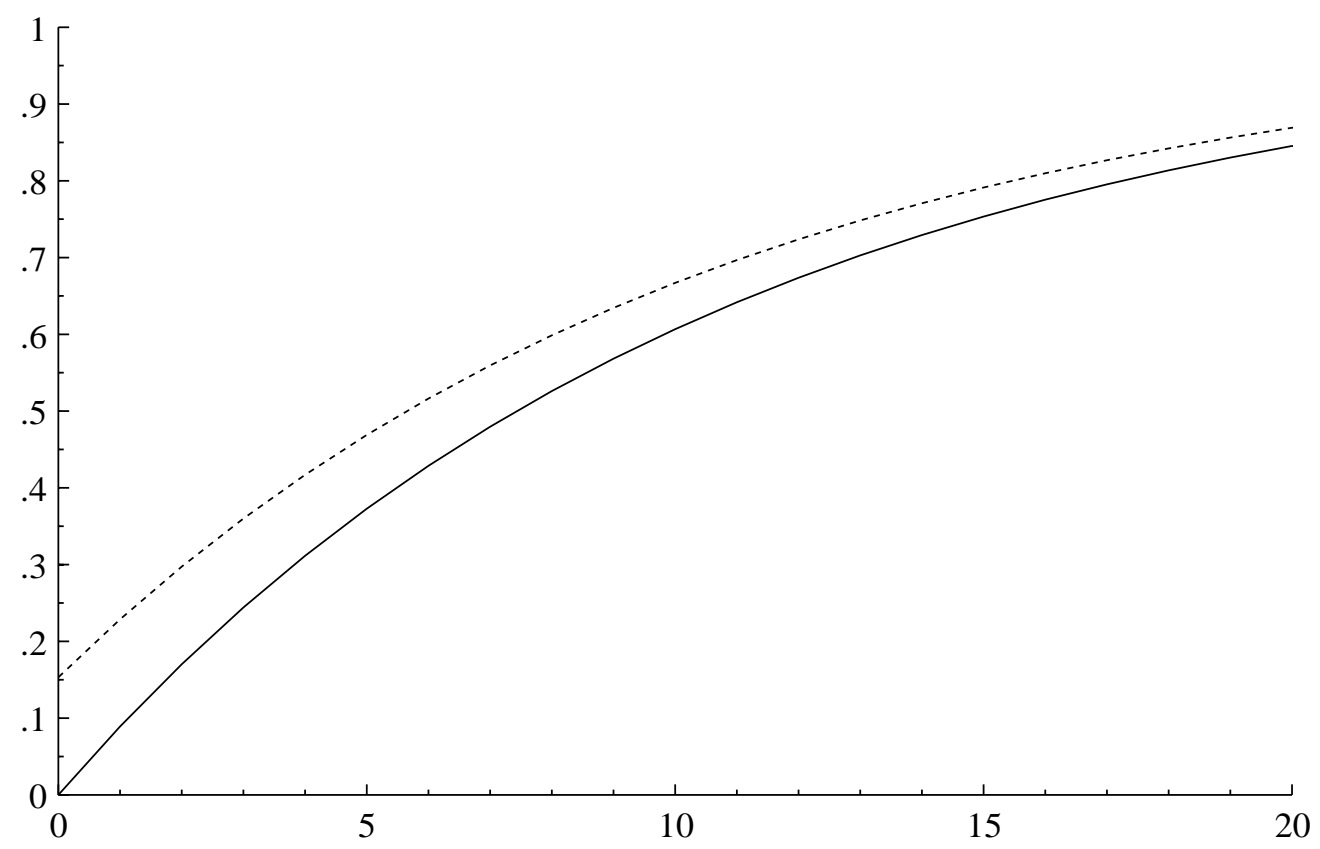


drawn-out adjustment process.

In (17), long-run homogeneity is imposed directly on the coefficients in the error correction term. This formulation emphasizes the effect on inflation of the disequilibrium in the long-run mark-up equation, i.e., (2). Alternatively, long-run unit homogeneity may be imposed by re-arrangement of the variables within the ECM in (17), obtaining (21).

$$
\begin{aligned}
& \widehat{\Delta p}_{t}=+\underset{[0.0062]}{0.0141} \Delta \text { pet }_{t}+\underset{[0.0086]}{0.0763 y_{t-1}^{\text {res }}} \\
& -\underset{[0.0066]}{0.0415}(p-u l c)_{t-1}-\underset{0.0394}{0.0035]}(p-i p)_{t-1} \\
& -\underset{[0.0022]}{0.0082}(p-p e t)_{t-1}+\underset{[0.0013]}{0.0096} D_{t}+\underset{[0.00058]}{0.00749} \\
& -\underset{[0.0009]}{0.0017} S_{1 t}-\underset{[0.0011]}{0.0009} S_{2 t}-{ }_{[0.0009]}^{0.0021} S_{3 t}
\end{aligned}
$$

For comparison with (17), White's (1980) heteroscedasticity-consistent standard errors appear in square brackets $[\cdot]$; see also MacKinnon and White (1985). Three distinct feedback terms appear in (21): $(p-u l c)_{t-1}$, $(p-i p)_{t-1}$, and $(p-p e t)_{t-1}$, each with its coefficient estimated unrestrictedly. These feedbacks are the negative logs of lagged real unit labour costs, real import prices, and real energy costs; cf. (4). These real prices are comparisons of nominal sectoral prices with the CPI, and so are also relative prices involving the price being explained by the equation. As such, these real prices focus attention on existing disequilibria of the domestic goods market relative to the domestic labour market, the foreign goods market, and the energy market. This interpretation is in the spirit of Juselius's (1992) model of Danish inflation and Metin's (1994) model of Turkish inflation, both of which examine the effects that numerous intraand inter-sectoral disequilibria have on inflation. Franz and Gordon (1993) find strong error correction feedbacks for models of German and American producer price indices, as does Ericsson (1994) for the U.S. consumer price index although, in both these studies, the error correction appears to be simply real unit labour costs. Because (21) is isomorphic to (17), the remainder of this paper refers to (17) alone, except when the representation in (21) is required. 


\section{Figure 14: Actual (-) and fitted (..) values of the underlying inflation rate.}

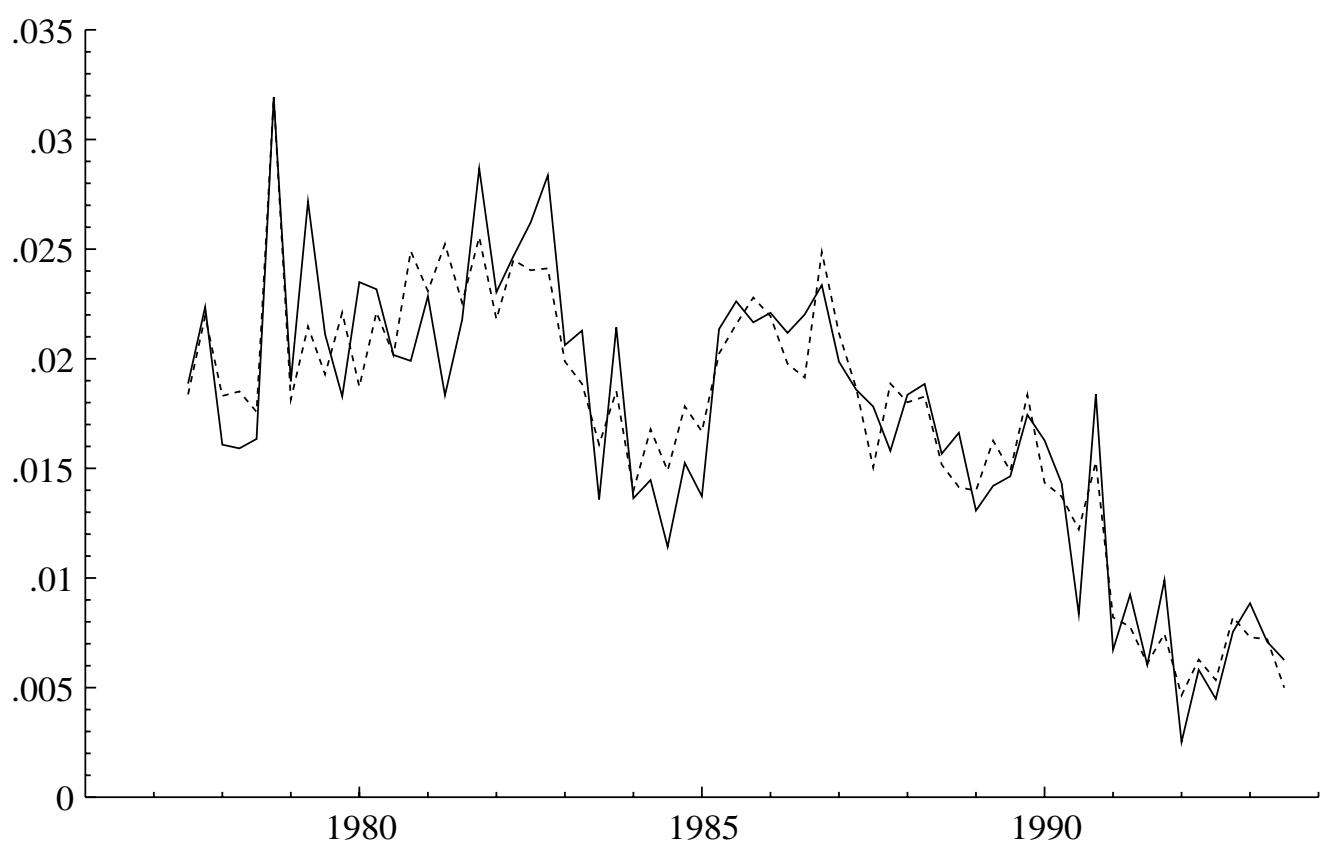

\subsection{Statistical Properties of the Model}

The statistical properties of the model can be assessed by what is not modelled, namely, the residuals. Residuals from full-sample and subsample estimates are both informative. Using a battery of residual diagnostic test statistics, this subsection shows that (17) appears well-specified, with empirically constant coefficients.

As noted in Section 5.2, the preferred equation performs well in terms of standard (full-sample) diagnostic tests. Empirically, the residuals are normally distributed, homoscedastic, and serially uncorrelated; and the null hypothesis of no omitted variables is easily accepted for a wide variety of variables. Figure 14 plots the actual and fitted values for $\Delta p_{t}$ and shows how well (17) explains the data.

Estimation over subsamples by a recursive algorithm provides an incisive tool for investigating constancy; cf. Brown, Durbin and Evans (1975) and Dufour (1982). Graphs efficiently summarize the large volume of output. Figures 15 and 16 portray two related functions of the residuals from recursive estimation: the first summarizes the numerical constancy of (17) and the second its statistical constancy. Figure 15 records the one-step residu- 
Figure 15: One-step residuals (-), with corresponding calculated equation standard errors as $0 \pm 2 \hat{\sigma}_{t}(\cdots)$.

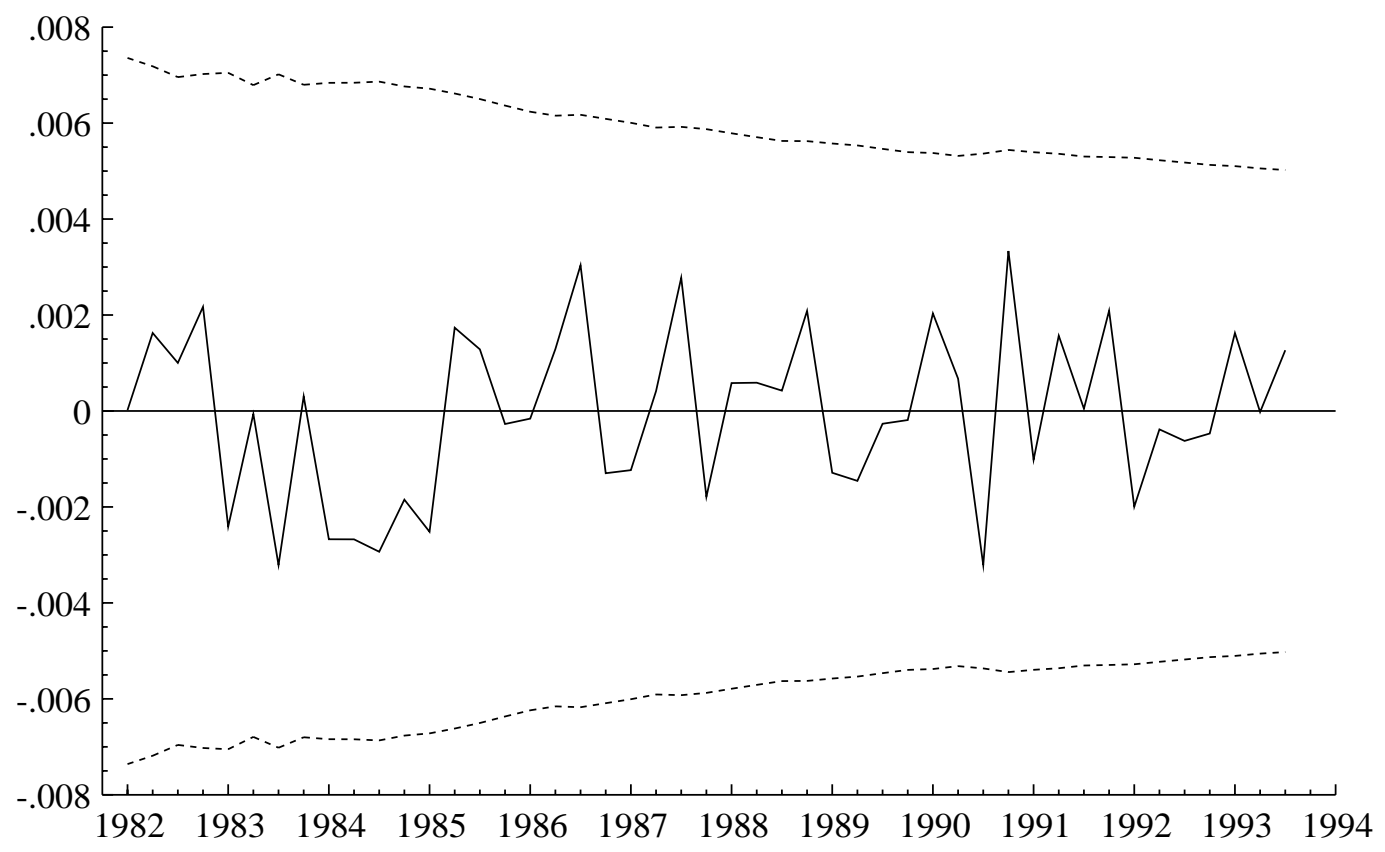

Figure 16: The sequence of break-point Chow statistics (-) over 1982-1993, with the statistics scaled by their one-off $5 \%$ critical values $(\cdots)$.

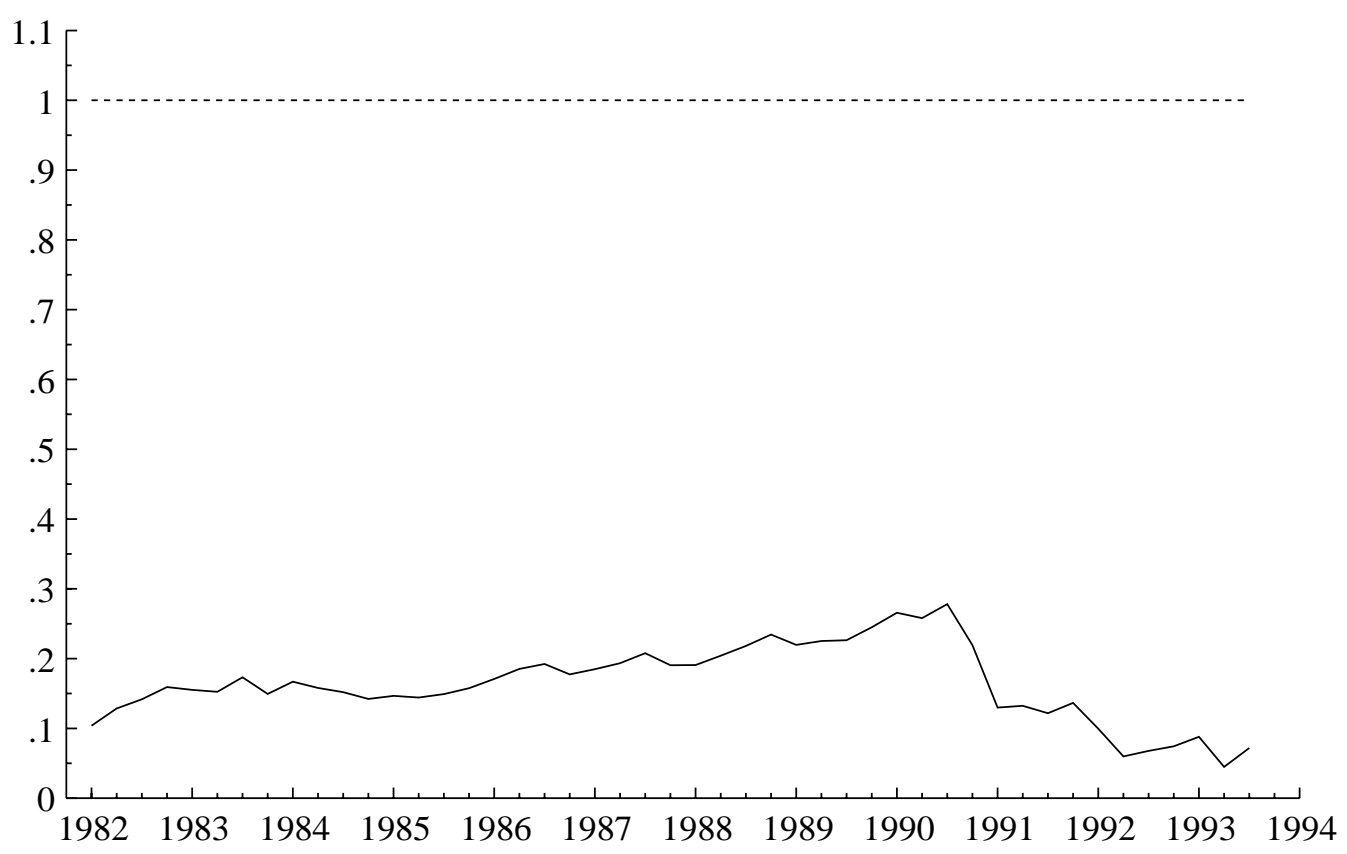


als and the corresponding calculated equation standard errors for (17), i.e., $\left\{y_{t}-\hat{\beta}_{t}^{\prime} x_{t}\right\}$ and $\left\{0 \pm 2 \hat{\sigma}_{t}\right\}$ in a common notation. The equation standard error $\hat{\sigma}$ varies little, declining slightly over time. Figure 16 plots the "breakpoint" Chow (1960) statistics for the sequence \{1982(1)-1993(3), 1982(2)1993(3), 1982(3)-1993(3), ..., 1993(2)-1993(3), 1993(3)\}. None of these Chow statistics is significant at even their one-off $5 \%$ levels. That is, there is no break of the sample into estimation and forecast periods such that the corresponding Chow statistic for predictive failure is significant.

Recursive estimates of individual coefficients in (17) vary little, both numerically and statistically. The estimates' stability provides additional evidence that the right-hand side variables in (17) are weakly exogenous for the parameters in this equation, in which case single equation estimation is valid and without loss of information relative to the VAR. Appendix 2 considers these recursive estimates in detail.

The empirical stability of (17) suggests that the inflationary process in Australia has remained largely unchanged during the 1980s and 1990s, even while inflation itself has declined. This stability exists in spite of known changes to institutions and economic structure over the period. The explanation for the decline in inflation, therefore, lies in what happened to actual nominal wages and labour productivity, the exchange rate, prices for Australia's trading partners, tariffs, petrol prices, and the output gap.

\subsection{Caveats}

Some caveats apply to this analysis of inflation, although their empirical import may be minimal. First, the model makes no allowance for recent increases in indirect taxes. Because the parameter estimates in (17) are very stable over time, one would then expect these tax increases to affect the residual of (17). Yet, the residuals over 1992-1993 have been typical in magnitude. As a potential explanation, difficult trading conditions may have forced domestic producers and retailers to absorb some of the tax effects. Second, the mark-up on imports between the dock and the final point of sale may have fallen recently with increased market openness and competition, as discussed in Dwyer and Lam (1994) and Dwyer and Romalis (1995). While the model in (17) includes a measure of the tariff rate, it has no variables that would account for additional such changes in the mark-up. From the statistical properties of (17), the consequences to 
(17) of such changes appear small empirically.

\section{ENCOMPASSING AND FORECASTING}

Two properties of (17) merit special attention, its ability to account for the results of other models of inflation (encompassing) and its potential usefulness in forecasting. Section 7.1 shows that (17) encompasses an alternate empirical model of inflation due to McTaggart and Hall (1993). Also, at a conceptual level, (17) encompasses several economic models of inflation, while each of those economic models provides only a partial explanation of CPI behaviour in Australia. Section 7.2 examines how (17) might be used for forecasting.

\subsection{Encompassing Alternative Models of Inflation}

Given the apparent empirical success of (17), it is natural to ask how its performance compares with other models of the Australian CPI. Numerous alternative models have been developed: see for example Fahrer and Myatt (1991), Coelli and Fahrer (1992), the papers in Blundell-Wignall (1992), Johansen (1992b), Knight (1992), and McTaggart and Hall (1993). Several characteristics distinguish (17) from such existing models. First, existing models are typically in differences only, thereby ignoring long-run levels relationships. Johansen (1992b) and Knight (1992) are exceptions in this respect. Second, many of the existing models have apparently significant direct effects of money growth and foreign CPI inflation on Australian CPI inflation. Third, the precise measure of the CPI tends to vary across models. To focus discussion, consider McTaggart and Hall's (1993) model.

McTaggart and Hall (1993) begin with a fourth-order ADL of an adjusted CPI inflation rate $\left(\Delta p^{a}\right)$, an OECD inflation rate $\left(\triangle p^{O E C D}\right)$, the spread between short- and long-term interest rates, and the growth rate of Australian M3 $(\Delta m) .{ }^{12}$ From that ADL, they obtained a more parsimonious model:

12 McTaggart and Hall's adjusted CPI $\left(P^{a}\right)$ is the headline CPI, net of some (but not all) of the components that were removed from the headline CPI to obtain the underlying CPI. 


$$
\begin{gathered}
\widehat{\Delta p_{t}^{a}}=+\underset{(0.091)}{0.321} \Delta p_{t-1}^{a}+\underset{(0.088)}{0.320 \Delta p_{t-2}^{a}} \\
+\underset{(0.087)}{0.350} \Delta p_{t-1}^{O E C D}+\underset{(0.044)}{0.112} \Delta m_{t-1}-\begin{array}{c}
0.0014 \\
(0.0021)
\end{array} \\
T=99[1967(3)-1992(1)] \quad R^{2}=0.583 \quad d w=2.03 .
\end{gathered}
$$

This model suggests the importance of foreign inflation and domestic monetary expansion as the proximate determinants of Australian inflation, contrasting with the structure in (17). In order to compare these two equations statistically, it is helpful to introduce the concept of encompassing.

Loosely speaking, encompassing is the ability of one model to account for the results of another model. Encompassing is a necessary property for any adequate empirical model: a model's inability to explain the properties of other models indicates the value of information contained in the other models, over and above that in the model being tested. Conversely, the ability of one model to encompass a second model implies that the second is redundant, given the first. Encompassing establishes an ordering across models such that an encompassing model serves as a sufficient statistic for all existing models; cf. Mizon and Richard (1986). Encompassing is particularly important when the alternative models have different economic and policy implications, as they do for (17) and (22).

Numerous test statistics for encompassing have been developed. The ones considered here are due to Cox $(1961,1962)$ (variance encompassing), Ericsson (1983) (a variant on the Cox statistic), and Sargan (1958) (reduced form encompassing). In addition, the classical $F$ statistic for testing a given model against the smallest comprehensive (nesting) model is included, since that statistic tests parameter encompassing.

Actual implementation of these tests is complicated by different definitions of the CPI, different sample periods for the models, and the lack of seasonal dummies in McTaggart and Hall's equation. To provide as balanced a comparison as possible, each model is tested twice, once using McTaggart and Hall's adjusted CPI and once using underlying CPI. The maximum sample periods available are used in both cases, which are 1977(3)-1992(1) and 1977(3)-1993(3) respectively. While the presence or absence of seasonal dummies is not a formal difficulty for the encompass- 
Table 3:

\section{Encompassing Statistics for Equation (17) and McTaggart and Hall's Equation for the CPI}

\begin{tabular}{|c|c|c|c|c|c|c|}
\hline \multirow[b]{3}{*}{ Statistic } & \multicolumn{6}{|c|}{ Null Hypothesis } \\
\hline & \multicolumn{3}{|c|}{$\begin{array}{l}\text { Equation (17) } \\
\end{array}$} & \multicolumn{3}{|c|}{ McTaggart and Hall } \\
\hline & Dist. & $P$ & $P^{a}$ & Dist. & $P$ & $P^{a}$ \\
\hline Cox & $\mathrm{N}(0,1)$ & -1.82 & -0.98 & $\mathrm{~N}(0,1)$ & $-10.40^{* *}$ & $-13.49^{* *}$ \\
\hline Ericsson & $\mathrm{N}(0,1)$ & 1.54 & 0.86 & $\mathrm{~N}(0,1)$ & $6.00^{* *}$ & $7.38^{* *}$ \\
\hline Sargan & $\chi^{2}(4)$ & 4.91 & 0.85 & $\chi^{2}(6)$ & $31.75^{* *}$ & $30.33^{* *}$ \\
\hline$F$ & $F(4, \cdot)$ & 1.25 & 0.20 & $F(6, \cdot)$ & $10.69^{* *}$ & $11.01^{* *}$ \\
\hline$\hat{\sigma}$ & & $0.251 \%$ & $0.357 \%$ & & $0.354 \%$ & $0.544 \%$ \\
\hline
\end{tabular}

Notes

1. The asymptotic distribution of each statistic under the null hypothesis appears under the column "Dist.".

2. The CPI measure is the underlying CPI for those statistics under the columns labeled $P$, and McTaggart and Hall's adjusted CPI for those statistics under columns labeled $P^{a}$.

3. See Doornik and Hendry (1994) for details on the statistics.

ing tests, seasonal dummies are highly significant if added to McTaggart and Hall's equation. In order to avoid rejecting (22) simply because (17) includes seasonal dummies and (22) does not, the tested version of McTaggart and Hall's equation includes seasonal dummies. The results appear in Table 3.

From the first two columns of numbers in Table 3, equation (17) appears to encompass McTaggart and Hall's equation. Only the Cox statistic (using $P$ ) is at all close to being statistically significant at the nominal $5 \%$ level, and the Cox statistic is known to over-reject in finite samples in even static models; see Pesaran (1974) and Ericsson (1986). By contrast, the final two columns in Table 3 show that McTaggart and Hall's equation does not encompass (17), regardless of the statistic used and regardless of the definition of CPI adopted. Put somewhat differently, lagged foreign inflation rates and domestic money growth rates are not important for explaining Australian inflation, conditional on including the growth of petrol prices, the tax dummy, and the lagged output gap and mark-up. Including the tax 
dummy in McTaggart and Hall's equation does not appreciably alter the results.

From additional similar tests, neither broad money nor short-term interest rates such as the 90-day rate for Bank accepted bills appear to be proximate influences on inflation. That said, monetary policy may and likely does affect inflation. Monetary transmission pathways may include the output gap, the exchange rate, and nominal wage formation inter alia, and through those variables affect inflation. To understand better the monetary transmission mechanism for inflation, a more complete, system analysis would be desirable; but such an analysis is beyond the scope of this paper. For discussion and illustrations of how such an approach would be undertaken, see Hendry and Mizon (1993), Juselius (1993), Doornik and Hendry (1994), and Hendry and Doornik (1994).

The encompassing of (22) by (17) raises an important methodological issue: (22) is a reduced form whereas (17) is "structural". While comparison of two such models might appear problematic, it is not. The precise meaning of "structural" bears on the explanation itself. First, "structural" sometimes means "conditional"; cf. Boswijk (1995) and Ericsson (1995). Unit labour costs, import prices, and petrol prices are empirically weakly exogenous in (17), so conditioning on their contemporaneous values is valid. In this context, the structural and reduced form aspects of the two models are not at issue. Encompassing simply provides a way of comparing two competing models. Second, and relatedly, the encompassing tests may be viewed as diagnostic checks on the two models. The tests evaluate whether lagged OECD inflation and Australian money growth are important omitted variables in (17), and whether the lagged mark-up and output gap are important omitted variables in (22). None of these variables are precluded a priori from either model, so the nature of an individual model (whether structural or reduced form) does not affect the validity of the encompassing tests. Third, even with empirically valid weak exogeneity, (17) is in effect a reduced form, with current inflation depending almost exclusively upon lagged information. When contemporaneous unit labour costs and import prices are included in (17), they are numerically and statistically unimportant. Contemporaneous petrol prices, which do appear in (17), are statistically significant but have a very small effect economically. Finally, Hendry and Mizon (1993) show how to calculate 
encompassing tests between a structural model (their sense of "structural") and a reduced form, where both are systems. The single-equation encompassing tests above are in the spirit of Hendry and Mizon's tests, noting that super exogeneity appears valid for (17).

At a more conceptual level, (17) encompasses a range of economic models for prices and inflation. Equation (17) embeds a variant of the priceinflation Phillips curve by relating price inflation to the output gap and so to the unemployment rate; cf. Ericsson, Irons and Tryon (1993). When rewritten as (21), (17) also includes both wage-price models (through $p-u l c$ ) and long-run purchasing power parity (through $p-i p$ ). However, as the empirical model (21) shows, each of these economic theories provides only a partial explanation of price behaviour in Australia. Several economic determinants are necessary to understand the behaviour of the Australian CPI.

Finally, because (17) is empirically constant, broad classes of models may not encompass (17), even in principle. In particular, models of inflation involving rational expectations may not encompass (17); see Hendry (1988), Ericsson and Hendry (1989), Favero and Hendry (1992), and Engle and Hendry (1993). Full testing of such a proposition turns on demonstrating that the equations for $u l c, i p$, and pet in the VAR are nonconstant. Empirically, the equation for $i p$ appears nonconstant, and possibly those for $u l c$ and pet as well. Again, a more complete, system analysis is the natural framework for testing such propositions but is beyond the scope of this paper.

\section{2 $\quad$ Forecasting}

Equation (17) is a highly parsimonious model of inflation, making it attractive as a tool for ex ante forecasts and counterfactual simulations. Apart from the current change in petrol prices, CPI inflation in the current quarter is based simply on the levels of the relevant indices and the output gap in the previous quarter. Thus forecasting one step ahead is straightforward. Multi-step ahead forecasts would require forecasts of unit labour costs, import prices, petrol prices, and the output gap, and so would most easily be carried out in a system (rather than a single equation) framework. Ex post forecasts can help assess the constancy of a model, so this subsection considers such forecasts, one step ahead, for the preferred equation. 
Given recent changes in the Australian economic environment, it is of interest to re-estimate (17) over an initial subsample and use that equation to forecast over the last few years. Figures 17 and 18 plot actual, fitted, and forecast values of inflation, where estimation is through 1989, and realized values of the right-hand side variables are used to construct the forecasts. The forecasts track the recent decline in inflation relatively well. As seen from these forecasts and from the recursive estimates of (17), there is no evidence of a structural break in the inflation process in 1990.

Ex ante forecasts and counterfactual simulations from (17) may be instructive from a policy perspective, but they have several important caveats. First, if only (17) is used, paths for unit labour costs, petrol prices, import prices, and the output gap must be given, precluding feedback from the CPI on to those variables. That is, the CPI is assumed to not Granger-cause the other variables. Second, counterfactual simulations assume robustness of the inflation equation to changes in the processes for unit labour costs, petrol prices, import prices, and the output gap (that is, super exogeneity). Implicitly, that assumes super exogeneity of the exchange rate as well. Third, the forecasts' standard errors are sizable, noting that the equation standard error in (17) is approximately $1 \%$ at an annual rate. Typically, multi-step ahead forecast standard errors are larger than their one-step counterparts, with the latter being $\pm 2 \%$ (at best) for a $95 \%$ confidence region. Finally, actual ex ante multi-step ahead forecasts would require modelling and forecasting the right-hand side variables, and their forecasts are themselves uncertain. Accounting for that uncertainty would almost invariably increase the standard errors of the CPI inflation forecasts. That said, forecasts of the average inflation rate over the next year or two could have a smaller confidence interval than any individual quarter's forecast; see Chong and Hendry (1986) and Campos (1992).

\section{CONCLUSIONS}

The error correction model in (17) has sensible economic and statistical properties, and it contains "value added" relative to existing models of Australian inflation. While it remains to be seen how the ECM will perform in the face of additional changes to the economy, continued low inflation through the 1990s appears to turn on sustained low growth rates in unit labour costs and import prices. 
Figure 17: Actual values (-) and fitted and forecast values $(\cdots)$ of the underlying inflation rate.

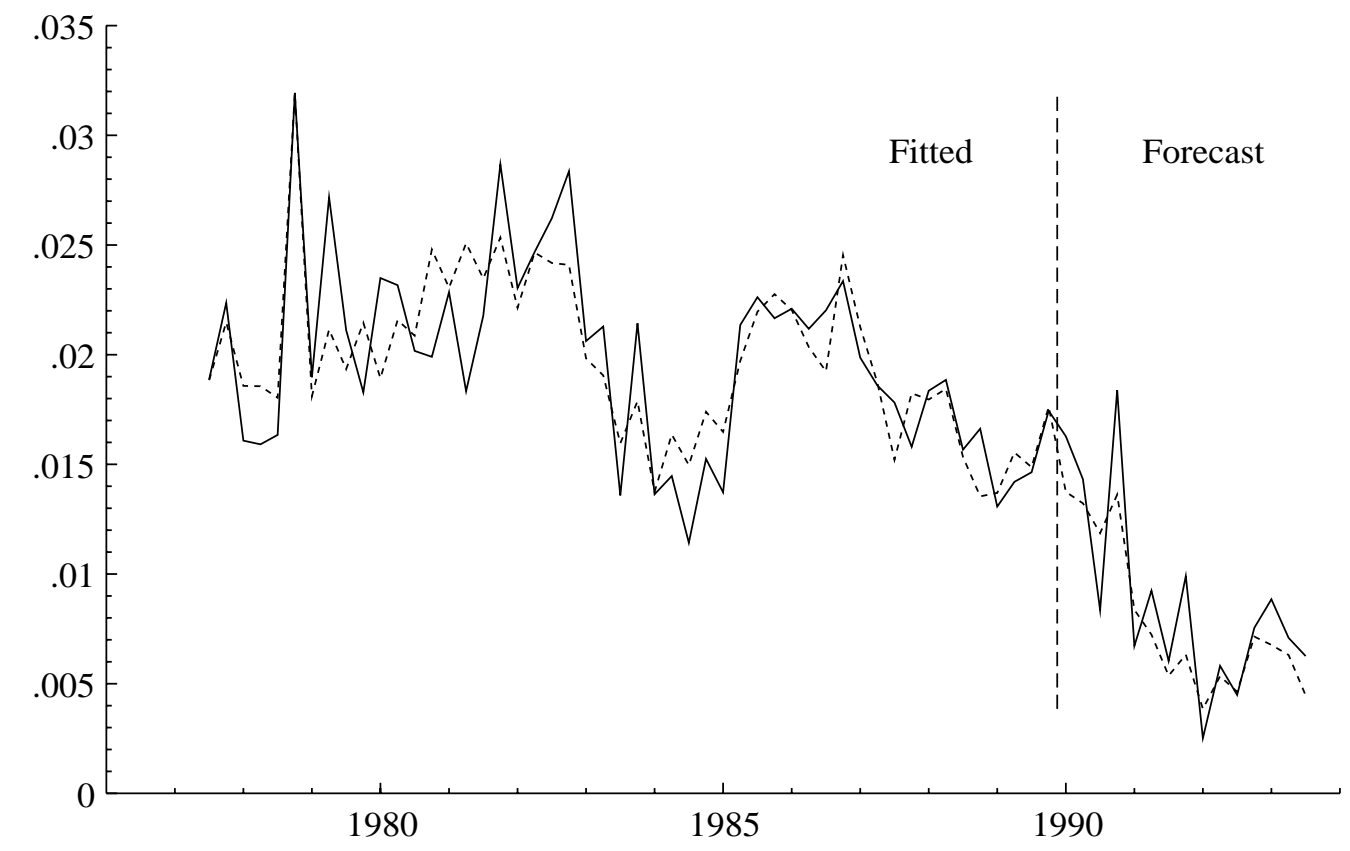

Figure 18: The underlying inflation rate (-) and its one-step-ahead forecasts $(\cdots)$, with \pm 2 forecast standard errors $(--)$.

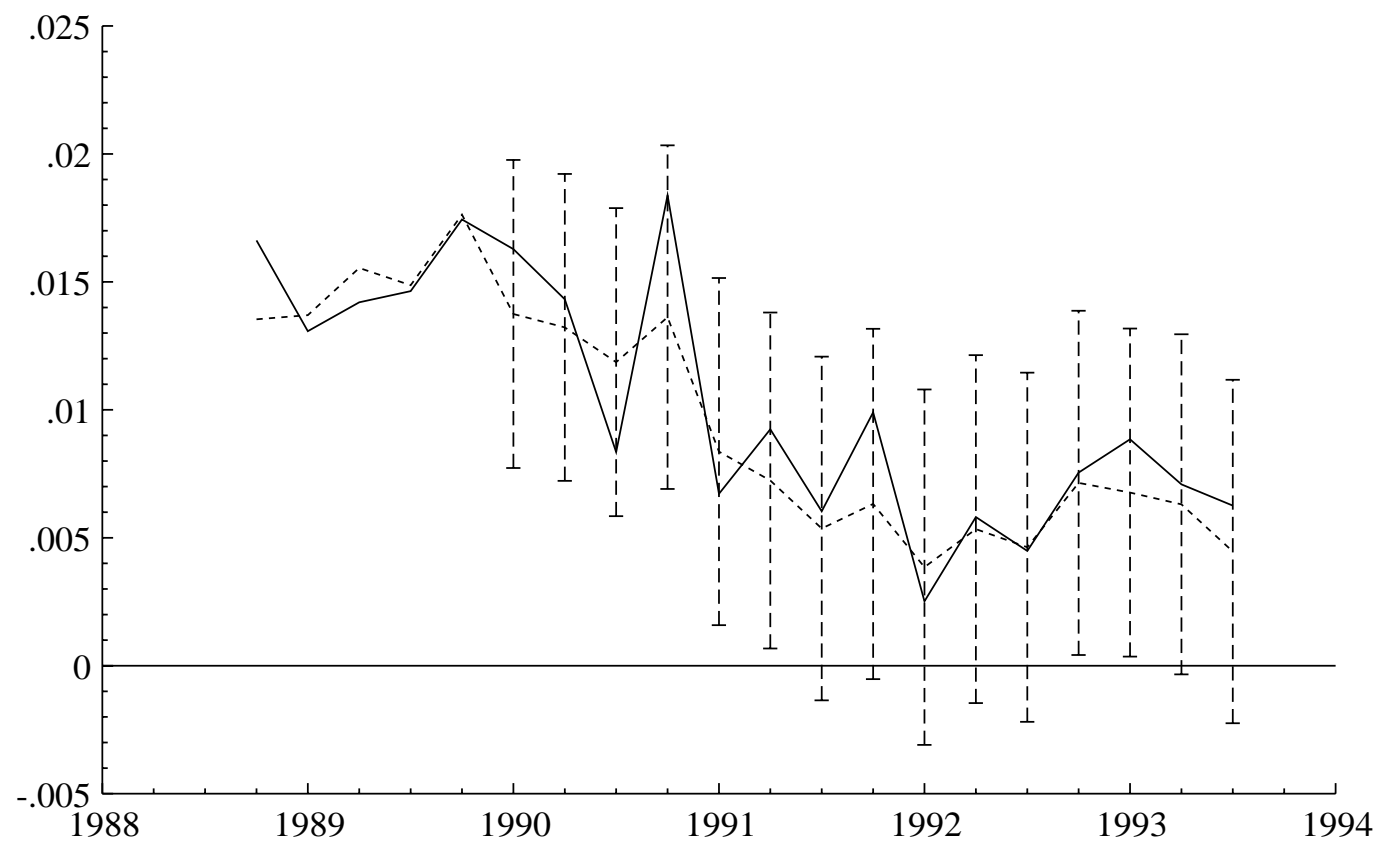


Justification for such inferences is founded on two counts. First, the estimated ECM is remarkably stable across a wide range of economic changes in the 1980s and 1990s. The coefficients are well-defined and do not alter significantly over this period. Second, many of the major economic changes that have occurred or are occurring should have their effect on the right-hand side variables themselves, and so need not imply any change in the coefficients of the CPI equation. For example, increased productivity and greater pressures on wage setters to remain internationally competitive may imply a lower outcome for unit labour costs rather than any change in the relationship between unit labour costs and consumer price inflation. Similarly, changes in tariffs may affect inflation through only the tariff-adjusted import price series.

Equation (17) does not capture some changes, which may bias inflation forecasts upwards. For example, increased competition due to internationalization may reduce the ability of domestic producers and retailers to widen their margins as the economy picks up, so the model may overstate the inflationary impact of the narrowing of the output gap. That said, such changes have been ongoing in the past decade, but appear to have had little effect on the coefficients in (17). 


\section{APPENDIX 1: DATA DEFINITIONS}

This appendix describes the data. Sections 1-7 list the definitions of the data and give their sources. Section 8 gives a detailed derivation of the underlying consumer price index. All data are quarterly, and the sample period is 1976(3)-1993(3). Seasonally adjusted series are denoted by SA, those not seasonally adjusted by NSA; and the Australian Bureau of Statistics is abbreviated as ABS.

\section{Headline Consumer Price Index $\left(P^{h}\right)$}

Definition. The consumer price index.

Units. $1989 / 90=100 .(\mathrm{NSA})$

Source. Consumer Price Index, ABS Catalogue No. 6401.0, Table 1.

\section{Underlying Consumer Price Index $(P)$}

Definition. The consumer price index, excluding fresh fruit and vegetables, mortgage interest and consumer credit charges, automotive fuel, and health services. The adjustment is explained and illustrated in Section 8 of this appendix.

Units. $1989 / 90=100$. (NSA)

Source. Consumer Price Index, ABS Catalogue No. 6401.0, Table 7.

\section{Unit Labour Costs $(U L C)$}

Definition. Nominal cost of non-farm labour per unit of non-farm output. Nominal unit labour costs are defined as:

$w s s+$ payroll taxes + fringe benefits taxes - employment subsidies real non-farm gross domestic product $\times \frac{\text { hours worked by all non-farm employees }}{\text { hours worked by non-farm wage and salary earners }}$, 
where wss refers to the wages, salaries and supplements of non-farm wage and salary earners. The class "wage and salary earners" is only a subset of all employed people in the non-farm economy, since it does not include the self-employed, employers, and unpaid family helpers who have a (nonfarm) job or business. Unit labour costs of wage and salary earners are scaled up to that for all employed by multiplying it by the ratio of hours worked by all employed people in the non-farm sector to the hours worked by non-farm wage and salary earners.

Units. Unit labour costs are indexed at 1966(3)-1973(2)=100 though, in this paper, the index is rebased at $1989 / 90=100$. (SA)

Source. Department of the Treasury, unpublished data. Recent data are listed in Australian Economic Indicators, ABS Catalogue No. 1350.0, Table 9.5, as "non-farm sector (nominal) Treasury index of average unit labour costs".

\section{Import Prices $(I P)$}

Definition. Tariff-adjusted import price index of merchandise imports, excluding exogenous imports, computers, and other lumpy import items.

Import prices are measured as the implicit price deflator on seasonally adjusted merchandise imports, excluding exogenous imports, computers and other lumpy import items. Exogenous imports are goods which are lumpy in nature, subject to government arrangements or significantly affected by factors other than the general level of economic activity in Australia. Specifically, this covers fuel, defence equipment, and ships, aircraft and other large items of equipment acquired by selected public and private enterprises. "Other lumpy import items" are those lumpy items which are similar in nature to exogenous imports but are not included in that category. For example, the purchase of an aeroplane by QANTAS is classified as an exogenous import, while the purchase of a tanker for the export of liquid natural gas (LNG) is classified as an other lumpy item.

The tariff rate is the ratio of taxes on international trade to the value of endogenous imports. The import implicit price deflator is multiplied by unity plus the tariff rate in order to derive tariff-adjusted import prices.

Units. The base period for the constant price series of merchandise imports 
is $1989 / 90=100$. (SA) Taxes and the value of endogenous imports are measured in \$A millions. (NSA)

Source. The constant and current price series of merchandise imports less exogenous items are taken from Balance of Payments, Australia, ABS Catalogue No. 5302.0, Tables 13 and 14. The constant and current price series of computers are unpublished data provided by the ABS. The constant and current price series of other lumpy items are unpublished data provided by the Department of the Treasury. Taxes on international trade are drawn from Australian National Accounts, ABS Catalogue No. 5206.0, Table 40, "Taxes, Fees and Fines".

\section{Petrol Prices $(P E T)$}

Definition. Automotive fuel price index.

Units. $1989 / 90=100$. (NSA)

Source. Consumer Price Index, ABS Catalogue No. 6401.0, Table 7.

\section{6. $\quad$ Private Final Demand $(Y)$}

Definition. Private final consumption expenditure and private gross fixed capital expenditure, excluding net second-hand purchases of equipment and non-dwelling construction from the public sector.

The variable $y^{\text {res }}$ is the residual of the log of private final demand regressed on a constant and trend for the full data period.

Units. Private final demand is measured in \$A millions, 1989/90 prices. (SA)

Source. Australian National Accounts, ABS Catalogue No. 5206.0, Table 59.

\section{Unit Capital Costs $(U C C)$}

Definition. Nominal cost of capital per unit of output.

The nominal unit capital costs are estimated as: 
non-farm GOS

real non-farm gross domestic product

where "non-farm GOS" means the "non-farm gross operating surplus of private corporate and unincorporated trading enterprises and public trading enterprises". Non-farm gross operating surplus of trading enterprises is calculated as total GOS of trading enterprises (excluding dwellings) less farm GOS. Real non-farm GDP(A), which is the average of the expenditure, income and production measures of GDP, is used in the denominator.

Units. $1989 / 90=100$. All variables used for constructing unit capital costs are seasonally adjusted.

Source. Australian National Accounts, ABS Catalogue No. 5206.0, Tables 55,65 , and 73 .

\section{Derivation of the Underlying Consumer Price Index}

The underlying consumer price index is defined as the total (headline) CPI, less fresh fruit and vegetables, mortgage interest charges, consumer credit charges, automotive fuel, and health services. This adjustment eliminates the sources of many of the breaks and of much of the volatility in the total CPI series. The derivation of the underlying CPI series is as follows.

\subsection{Estimated Contributions}

The underlying CPI series is calculated by subtracting the contributions for each of the excluded items from the total CPI. The data source for the contributions is the ABS publication Consumer Price Index, Catalogue No. 6401.0, Table 7. For example, the adjustments for 1993(3) appear in the following table.

Total CPI

less:

Fresh fruit and vegetables

Mortgage interest charges

Consumer credit charges

Automotive fuel

Health services

Adjusted contribution
109.8

6.57

2.34

5.11

4.53

89.74 
Quarterly percentage changes are calculated using the adjusted series.

\subsection{Changes in Weights}

Breaks in the adjusted series occur, however, wherever the CPI has been reweighted. Since the contribution of each series to the CPI is provided at both the old and new weight when the weight is changed, estimation of the growth in the index is straightforward. Consider, for example, the reweighting at 1992(2). The published series contains data to 1992(1) at the 11th series weights and data at the 12th series weights thereafter. Data for 1992(2) are supplied at both the 11th and 12th series weights, as shown in the following table.

\begin{tabular}{lccc}
\hline Month & $\begin{array}{c}\text { March 92 } \\
\text { 11th }\end{array}$ & $\begin{array}{c}\text { June 92 } \\
\text { 11th }\end{array}$ & $\begin{array}{c}\text { June 92 } \\
\text { 12th }\end{array}$ \\
& & & \\
Total CPI & 107.6 & 107.3 & 107.3 \\
less: & & & \\
Fresh fruit and vegetables & 1.73 & 1.62 & 1.52 \\
$\quad$ Mortgage interest charges & 6.29 & 5.95 & 7.09 \\
Consumer credit charges & 2.83 & 2.77 & 2.68 \\
Automotive fuel & 4.66 & 4.68 & 5.04 \\
$\quad$ Health services & 4.60 & 4.28 & 4.25 \\
Adjusted contribution & 87.49 & 88.0 & 86.72 \\
\hline
\end{tabular}

These weights imply that the underlying CPI grew by 0.58 per cent in 1992(2).

A similar calculation is made for the 1986(4) 11th series reweighting, with the exception that mortgage interest charges and consumer credit charges were not considered since they were not included in the 10th series CPI. No adjustment has been made for the 1982 10th series reweighting since there is no break in the automotive fuel series (see below), and the weighting changes in fruit and vegetables and health services broadly offset each other.

\subsection{Adjustments before 1982 for Automotive Fuel}

Automotive fuel poses a special problem in that it was not separately identified in the CPI in the (pre-1982) 9th series, and so no contributions series exists. An index exists for the price of automotive fuel, beginning 
in the early 1970s, but no weight for the 9th series is currently available. Instead, the 10th series automotive fuel weight was used to determine the contribution of the automotive fuel price index to the CPI for the 9th series. While this adjustment does not reflect the true weight of petrol in the CPI before 1982, it is a reasonable approximation to make with existing data.

\subsection{The Underlying Consumer Price Index}

The underlying CPI is constructed using the percentage changes calculated above, and is rebased at $1989 / 90=100$. 


\section{APPENDIX 2: DESIGN OF THE EMPIRICAL ECM}

This appendix discusses several of the steps taken to obtain the ECM in (17) and examines in greater detail the recursive estimates of the coefficients in (17). This simplification to (17) has numerous motivations. Because of its parsimony and more orthogonal regressors, (17) is more easily interpreted than the unrestricted ADL or VAR. Also, the coefficients in (17) are more precisely estimated than those in the ADL and the VAR, providing tighter inferences generally and higher potential power for tests of mis-specification.

Initially, the vector autoregression for the system cointegration analysis is simplified from a fourth-order VAR to a first-order VAR, where the variables in the VARs are $p, u l c, i p$, pet, a constant, and centered seasonal dummies. Table A1 reports the $F$ statistics and related calculations for that simplification, where the longest lag on all variables is deleted repeatedly from the VAR. None of the $F$ statistics comparing the initial, intermediate, and final VARs is significant; and the Schwarz criterion becomes steadily more negative as the lag length is shortened. The Schwarz criterion in effect adjusts a measure of the model's goodness of fit (the $\log$ of the determinant of the estimated error variance matrix) for the model's degree of parsimony. A smaller Schwarz criterion indicates a better-fitting model for a given number of parameters, or a more parsimonious model for a given goodness of fit.

Having tested for and found weak exogeneity for unit labour costs, import prices, and petrol prices (Table 2), a fourth-order autoregressive distributed lag for the CPI is simplified to the ECM in (17). Table A2 lists the estimates of the coefficients for the fourth-order ADL, where the ADL has been transformed into its unrestricted ECM representation (11). The following variables do not appear either numerically or statistically significant.

(i) The third lag on $\Delta p, \Delta u l c, \Delta i p, \Delta p e t$, and $\Delta y$;

(ii) The second lag on $\Delta p, \Delta u l c, \Delta i p, \Delta p e t$, and $\Delta y$; and

(iii) The first lag on $\Delta p, \Delta u l c, \Delta i p, \Delta p e t$, and $\Delta y$.

Three additional sets of reductions are considered: 
Table A1:

$F$ and Related Statistics for the Sequential Reduction from the Fourth-order VAR to the First-order VAR

\begin{tabular}{|c|c|c|c|c|c|c|}
\hline \multicolumn{4}{|c|}{ Null Hypothesis } & \multicolumn{3}{|c|}{ Maintained Hypothesis } \\
\hline System & $k$ & $\mathcal{L}$ & $S C$ & $\overline{\text { VAR(4) }}$ & VAR(3) & VAR(2) \\
\hline $\operatorname{VAR}(4)$ & 80 & 1111.5 & -29.06 & - & & \\
\hline$\downarrow$ & & & & - & & \\
\hline $\operatorname{VAR}(3)$ & 64 & 1101.8 & -29.79 & $\begin{array}{c}0.82 \\
{[0.66]}\end{array}$ & & \\
\hline$\downarrow$ & & & & $(16,128)$ & & \\
\hline $\operatorname{VAR}(2)$ & 48 & 1091.0 & -30.49 & $\begin{array}{c}0.91 \\
{[0.61]}\end{array}$ & $\begin{array}{c}1.02 \\
{[0.44]}\end{array}$ & \\
\hline$\downarrow$ & & & & $(32,156)$ & $(16,141)$ & \\
\hline $\operatorname{VAR}(1)$ & 32 & 1079.2 & -31.15 & $\begin{array}{c}1.00 \\
{[0.48]} \\
(48,163)\end{array}$ & $\begin{array}{c}1.11 \\
{[0.32]} \\
(32,171)\end{array}$ & $\begin{array}{c}1.21 \\
{[0.26]} \\
(16,153)\end{array}$ \\
\hline
\end{tabular}

Notes

1. The first four columns report the vector autoregression with its order, and for that system: the number of unrestricted parameters $k$, the $\log$-likelihood $\mathcal{L}$, and the Schwarz criterion $S C$.

2. The three entries within a given block of numbers in the last three columns are: the approximate $F$ statistic for testing the null hypothesis (indicated by the model to the left of the entry) against the maintained hypothesis (indicated by the model above the entry), the tail probability associated with that value of the $F$ statistic (in square brackets), and the degrees of freedom for the $F$ statistic (in parentheses). See Doornik and Hendry (1994) for details underlying these calculations. 
Table A2:

The Unrestricted Error Correction Representation for the Underlying CPI

\begin{tabular}{|c|c|c|c|c|}
\hline \multirow{2}{*}{ Variable } & \multicolumn{4}{|c|}{$\operatorname{Lag} i$} \\
\hline & 0 & 1 & 2 & 3 \\
\hline$\Delta p_{t-i}$ & $\begin{array}{r}-1.0 \\
(-)\end{array}$ & $\begin{array}{c}-0.063 \\
(0.141)\end{array}$ & $\begin{array}{c}0.136 \\
(0.138)\end{array}$ & $\begin{array}{c}-0.043 \\
(0.146)\end{array}$ \\
\hline$\Delta u l c_{t-i}$ & $\begin{array}{c}0.042 \\
(0.031)\end{array}$ & $\begin{array}{c}-0.020 \\
(0.028)\end{array}$ & $\begin{array}{c}-0.021 \\
(0.029)\end{array}$ & $\begin{array}{c}-0.007 \\
(0.028)\end{array}$ \\
\hline$\Delta i p_{t-i}$ & $\begin{array}{c}0.021 \\
(0.016)\end{array}$ & $\begin{array}{c}-0.011 \\
(0.019)\end{array}$ & $\begin{array}{c}-0.003 \\
(0.021)\end{array}$ & $\begin{array}{c}0.000 \\
(0.019)\end{array}$ \\
\hline$\Delta p e t_{t-i}$ & $\begin{array}{c}0.011 \\
(0.007)\end{array}$ & $\begin{array}{c}0.006 \\
(0.009)\end{array}$ & $\begin{array}{c}0.003 \\
(0.009)\end{array}$ & $\begin{array}{c}0.007 \\
(0.008)\end{array}$ \\
\hline$\Delta y_{t-i}$ & $\begin{array}{r}-0.020 \\
(0.048)\end{array}$ & $\begin{array}{c}-0.039 \\
(0.054)\end{array}$ & $\begin{array}{c}-0.009 \\
(0.045)\end{array}$ & $\begin{array}{c}-0.022 \\
(0.042)\end{array}$ \\
\hline$p_{t-i}$ & & $\begin{array}{r}-0.098 \\
(0.034)\end{array}$ & & \\
\hline$u l c_{t-i}$ & & $\begin{array}{c}0.051 \\
(0.028)\end{array}$ & & \\
\hline$i p_{t-i}$ & & $\begin{array}{c}0.046 \\
(0.016)\end{array}$ & & \\
\hline pet $_{t-i}$ & & $\begin{array}{c}0.005 \\
(0.005)\end{array}$ & & \\
\hline$y_{t-i}^{r e s}$ & & $\begin{array}{c}0.080 \\
(0.027)\end{array}$ & & \\
\hline$D_{t}$ & $\begin{array}{c}0.011 \\
(0.004)\end{array}$ & & & \\
\hline$S_{i t}$ & $\begin{array}{r}-0.0087 \\
(0.0288)\end{array}$ & $\begin{array}{c}-0.0021 \\
(0.0013)\end{array}$ & $\begin{array}{c}-0.0011 \\
(0.0011)\end{array}$ & $\begin{array}{r}-0.0022 \\
(0.0012)\end{array}$ \\
\hline
\end{tabular}

$T=65$ [1977(3)-1993(3)] $\quad \mathrm{R}^{2}=0.9016 \quad \hat{\sigma}=0.268 \%$

$d w=2.04 \quad L M_{p}: F(1,36)=0.33$

$A R: F(5,31)=0.50 \quad A R C H: F(4,28)=0.25$

Normality $: \chi^{2}(2)=0.34 \quad R E S E T: F(1,35)=0.17$

Notes

1. The dependent variable is $\Delta p_{t}$. Even so, the equation is in levels, not in differences, noting the presence of $p_{t-1}$.

2. The variable $S_{0 t}$ is the constant term; and $S_{1 t}, S_{2 t}$, and $S_{3 t}$ are centered seasonal dummies for the first, second, and third quarters, respectively. 
(iv) The sum of the coefficients on $u l c_{t-1}, i p_{t-1}$, and $p e t_{t-1}$ equals the negative of the coefficient on $p_{t-1}$, i.e., long-run homogeneity in prices is satisfied;

(v) $\Delta u l c_{t}$ and $\Delta i p_{t}$ have zero coefficients; and

(vi) $\Delta y_{t}$ has a zero coefficient.

Treated sequentially, these six restrictions obtain the following seven models.

Model 1: The unrestricted ECM in Table A2.

Model 2: Model 1, excluding the third lag on $\Delta p, \Delta u l c, \Delta i p, \Delta p e t$, and $\Delta y$.

Model 3: Model 2, excluding the second lag on $\Delta p, \Delta u l c, \Delta i p, \Delta p e t$, and $\Delta y$.

Model 4: Model 3, excluding the first lag on $\Delta p, \Delta u l c, \Delta i p, \Delta p e t$, and $\Delta y$.

Model 5: Model 4, imposing long-run price homogeneity.

Model 6: Model 5, excluding $\Delta u l c_{t}$ and $\Delta i p_{t}$.

Model 7: Model 6, excluding $\Delta y_{t}$.

So, for example, Model 2 is Model 1 plus reduction (i); Model 3 is Model 1 plus reductions (i)-(ii); and Model 3 is also Model 2 plus reduction (ii).

Table A3 lists the estimates for Model 4 and shows how little the estimates change from imposing the first three reductions. Table A3 also clarifies how the remaining three restrictions appear reasonable.

To facilitate formally assessing whether or not the sequence of reductions (i)-(vi) is valid, and if not, where not, statistics associated with the implied reductions are calculated for all model pairs, and not only for adjacent models. Table A4 reports this information, including the estimated equation standard error $\hat{\sigma}$ and the Schwarz criterion for each model, the $F$ statistics for all model pairs, and the associated tail probability values. The equation standard error is relatively constant across the entire simplification path; and the Schwarz criterion declines steadily through Model 6, remaining virtually unchanged between Model 6 and Model 7. Only that last reduction (excluding $\Delta y_{t}$ ) is statistically significant at the $5 \%$ level; 
Table A3:

A Partially Restricted Error Correction Representation for the Underlying CPI

\begin{tabular}{|c|c|c|c|c|}
\hline \multirow{2}{*}{ Variable } & \multicolumn{4}{|c|}{$\operatorname{Lag} i$} \\
\hline & 0 & 1 & 2 & 3 \\
\hline$\Delta p_{t-i}$ & $\begin{array}{r}-1.0 \\
(-)\end{array}$ & & & \\
\hline$\Delta u l c_{t-i}$ & $\begin{array}{c}0.033 \\
(0.022)\end{array}$ & & & \\
\hline$\Delta i p_{t-i}$ & $\begin{array}{c}0.012 \\
(0.013)\end{array}$ & & & \\
\hline$\Delta p t_{t-i}$ & $\begin{array}{c}0.010 \\
(0.006)\end{array}$ & & & \\
\hline$\Delta y_{t-i}$ & $\begin{array}{r}-0.049 \\
(0.030)\end{array}$ & & & \\
\hline$p_{t-i}$ & & $\begin{array}{r}-0.0884 \\
(0.0136)\end{array}$ & & \\
\hline$u l c_{t-i}$ & & $\begin{array}{c}0.0404 \\
(0.0143)\end{array}$ & & \\
\hline$i p_{t-i}$ & & $\begin{array}{c}0.0417 \\
(0.0055)\end{array}$ & & \\
\hline pet $_{t-i}$ & & $\begin{array}{c}0.0072 \\
(0.0030)\end{array}$ & & \\
\hline$y_{t-i}^{r e s}$ & & $\begin{array}{l}0.0641 \\
(0.0124)\end{array}$ & & \\
\hline$D_{t}$ & $\begin{array}{c}0.0103 \\
(0.0028)\end{array}$ & & & \\
\hline$S_{i t}$ & $\begin{array}{c}0.0032 \\
(0.0140)\end{array}$ & $\begin{array}{c}-0.0022 \\
(0.0010)\end{array}$ & $\begin{array}{r}-0.0007 \\
(0.0009)\end{array}$ & $\begin{array}{r}-0.0024 \\
(0.0009)\end{array}$ \\
\hline \multicolumn{5}{|c|}{$T=65[1977(3)-1993(3)] \quad \mathrm{R}^{2}=0.8838 \quad \hat{\sigma}=0.244 \%$} \\
\hline \multicolumn{5}{|c|}{$d w=2.13 \quad L M_{p}: F(1,51)=0.09$} \\
\hline \multicolumn{5}{|c|}{$A R: F(5,46)=0.27 \quad A R C H: F(4,43)=0.95$} \\
\hline \multicolumn{5}{|c|}{ Normality $: \chi^{2}(2)=1.19 \quad \operatorname{RESET}: F(1,50)=1.00$} \\
\hline \multicolumn{5}{|c|}{ Hetero: $F(22,28)=0.92$} \\
\hline
\end{tabular}

Notes

See the notes for Table A2. 
Table A4:

$F$ and Related Statistics for the Sequential Reduction from the Fourth-order ADL Model in Table A2

\begin{tabular}{|c|c|c|c|c|c|c|c|c|c|}
\hline \multicolumn{4}{|c|}{ Null Hypothesis } & \multicolumn{6}{|c|}{ Maintained Hypothesis (Model Number) } \\
\hline Model & $k$ & $\hat{\sigma}$ & $S C$ & 1 & 2 & 3 & 4 & 5 & 6 \\
\hline 1 & 29 & $0.268 \%$ & -10.58 & - & & & & & \\
\hline$\downarrow$ (i) & & & & - & & & & & \\
\hline $\begin{array}{l}2 \\
\downarrow \quad \text { (ii) }\end{array}$ & 24 & $0.255 \%$ & -10.86 & $\begin{array}{c}0.24 \\
{[0.94]} \\
(5,36)\end{array}$ & & & & & \\
\hline $\begin{array}{l}3 \\
\downarrow \quad \text { (iii) }\end{array}$ & 19 & $0.250 \%$ & -11.11 & $\begin{array}{c}0.40 \\
{[0.94]} \\
(10,36)\end{array}$ & $\begin{array}{c}0.62 \\
{[0.69]} \\
(5,41)\end{array}$ & & & & \\
\hline $\begin{array}{l}4 \\
\downarrow \text { (iv) }\end{array}$ & 14 & $0.244 \%$ & -11.37 & $\begin{array}{c}0.43 \\
{[0.96]} \\
(15,36)\end{array}$ & $\begin{array}{c}0.59 \\
{[0.82]} \\
(10,41)\end{array}$ & $\begin{array}{c}0.58 \\
{[0.71]} \\
(5,46)\end{array}$ & & & \\
\hline $\begin{array}{l}5 \\
\downarrow \quad(\mathrm{v})\end{array}$ & 13 & $0.242 \%$ & -11.43 & $\begin{array}{c}0.41 \\
{[0.97]} \\
(16,36)\end{array}$ & $\begin{array}{c}0.54 \\
{[0.86]} \\
(11,41)\end{array}$ & $\begin{array}{l}0.50 \\
{[0.81]} \\
(6,46)\end{array}$ & $\begin{array}{l}0.09 \\
{[0.77]} \\
(1,51)\end{array}$ & & \\
\hline $\begin{array}{l}6 \\
\downarrow \quad(\mathrm{vi})\end{array}$ & 11 & $0.244 \%$ & -11.51 & $\begin{array}{c}0.49 \\
{[0.95]} \\
(18,36)\end{array}$ & $\begin{array}{c}0.65 \\
{[0.80]} \\
(13,41)\end{array}$ & $\begin{array}{c}0.70 \\
{[0.69]} \\
(8,46)\end{array}$ & $\begin{array}{c}0.93 \\
{[0.43]} \\
(3,51)\end{array}$ & $\begin{array}{c}1.37 \\
{[0.26]} \\
(2,52)\end{array}$ & \\
\hline 7 & 10 & $0.251 \%$ & -11.50 & $\begin{array}{c}0.66 \\
{[0.84]} \\
(19,36)\end{array}$ & $\begin{array}{c}0.89 \\
{[0.58]} \\
(14,41)\end{array}$ & $\begin{array}{c}1.08 \\
{[0.39]} \\
(9,46)\end{array}$ & $\begin{array}{c}1.78 \\
{[0.15]} \\
(4,51)\end{array}$ & $\begin{array}{l}2.38 \\
{[0.080]} \\
(3,52)\end{array}$ & $\begin{array}{l}4.34 \\
{[0.042]} \\
(1,54)\end{array}$ \\
\hline
\end{tabular}

Notes

1. The first four columns report the model number (with reduction number), and for that model: the number of unrestricted parameters $k$, the estimated equation standard error $\hat{\sigma}$, and the Schwarz criterion $S C$. The text of Appendix 2 defines the models and reductions.

2. The three entries within a given block of numbers in the last six columns are: the $F$ statistic for testing the null hypothesis (indicated by the model number to the left of the entry) against the maintained hypothesis (indicated by the model number above the entry), the tail probability associated with that value of the $F$ statistic (in square brackets), and the degrees of freedom for the $F$ statistic (in parentheses). 
Figure A1: Recursive estimates (-) of the coefficients on $\Delta p e t_{t}$ and $y_{t-1}^{r e s}$, with \pm 2 estimated standard errors $(\cdots)$.

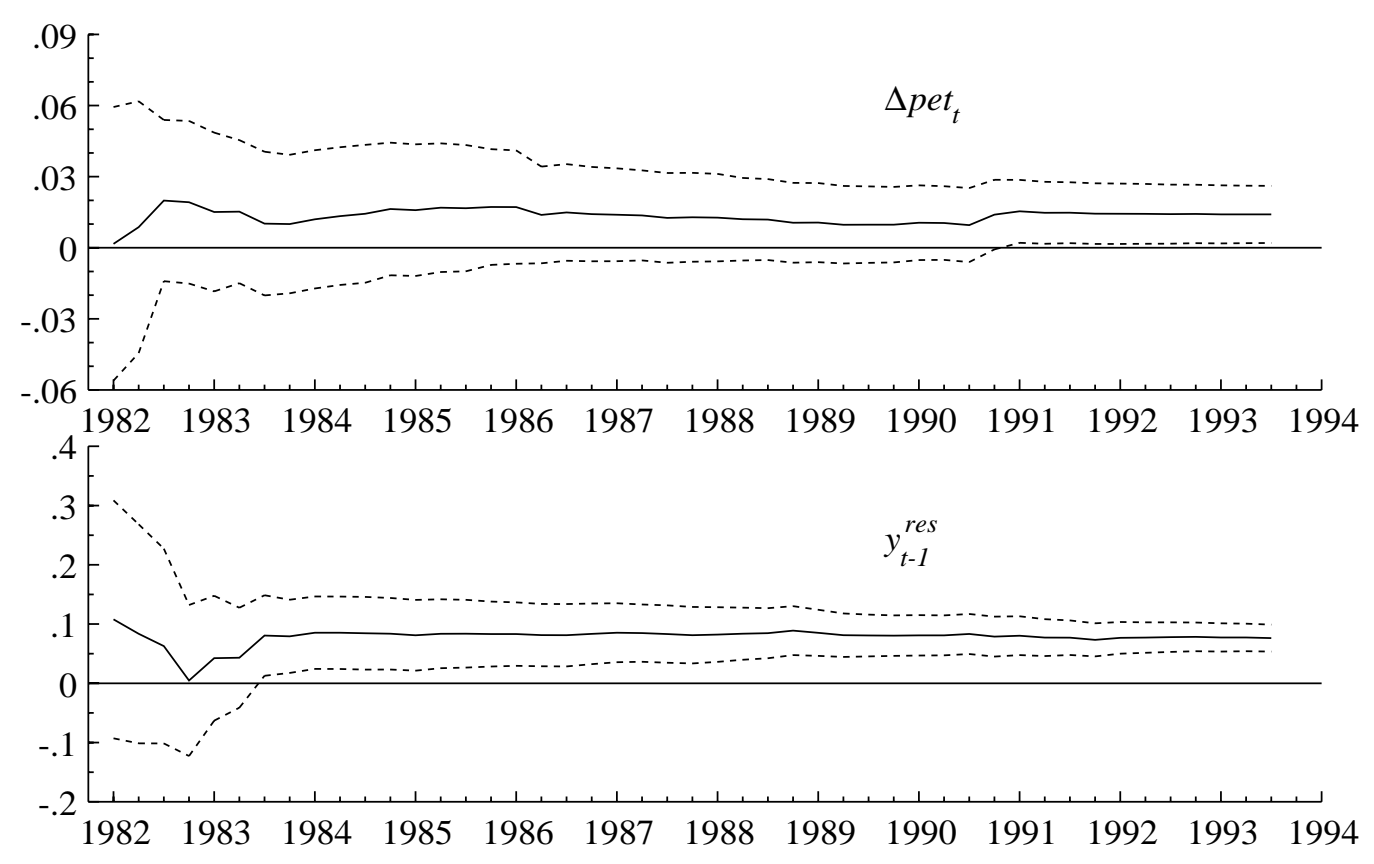

and it is only barely so, and only when considered by itself and not in conjunction with previous reductions. Appendix 3 develops an alternative model that includes changes in the output gap. Other orderings of (i)-(vi) generate somewhat different statistics, but those resulting statistics are unlikely to be highly statistically significant because the reduction of (i)-(vi) as a whole appears valid, with $F(19,36)=0.66$ and a $p$-value of 0.84 .

Figures A1-A3 show the recursively estimated coefficients of the economic variables in (17) and plus-or-minus twice their recursively estimated standard errors, conventionally denoted $\hat{\beta}_{t}$ and $\hat{\beta}_{t} \pm 2 e s e\left(\hat{\beta}_{t}\right)$ respectively. To provide more interpretable graphs, (17) has been parameterized as (21), in which all coefficients are unrestricted. Coefficients vary only slightly relative to their ex ante standard errors, and the two dominant feedback terms are highly significant by 1986 . 
Figure A2: Recursive estimates (-) of the coefficients on $(p-u l c)_{t-1}$ and $(p-i p)_{t-1}$, with \pm 2 estimated standard errors $(\cdots)$.

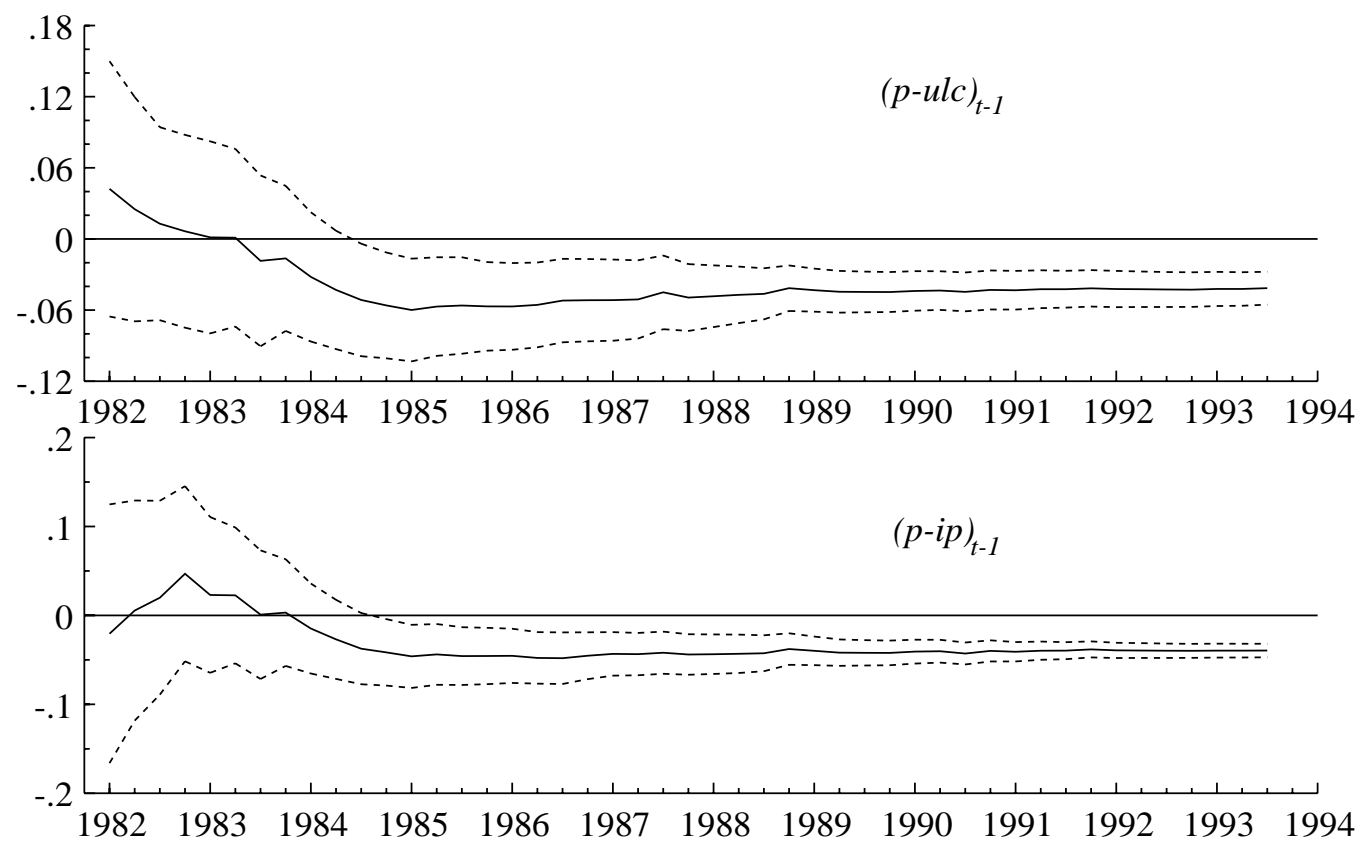

Figure A3: Recursive estimates (-) of the coefficients on $(p-p e t)_{t-1}$ and the constant, with \pm 2 estimated standard errors $(\cdots)$.

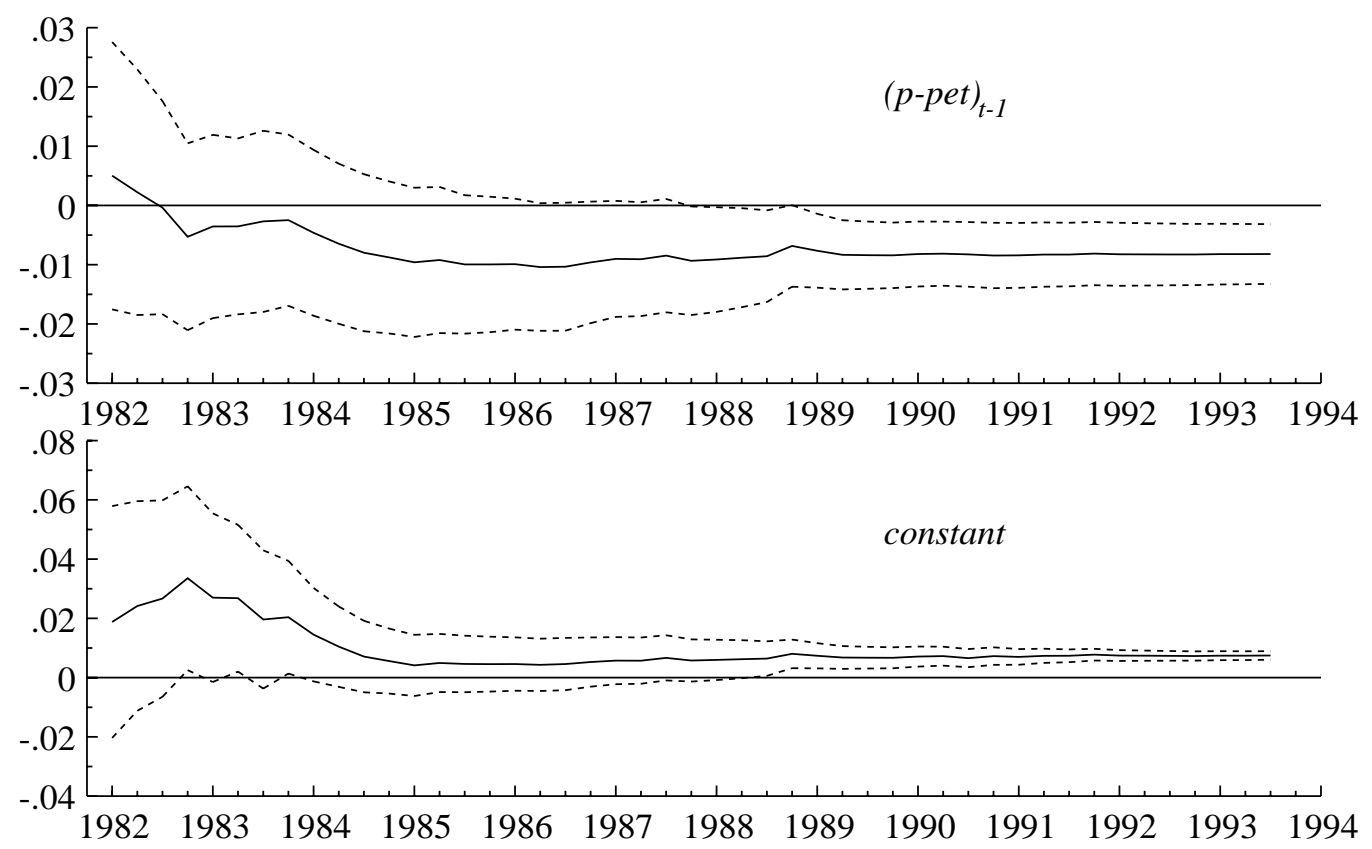




\section{APPENDIX 3: AN ALTERNATIVE MODEL OF THE CPI}

This appendix discusses the measure of the output gap $y^{\text {res }}$, and then develops an alternative model to (17) that captures dynamic effects of the output gap on inflation.

In (17) and in (A1) below, the output gap is incorporated explicitly as $y^{\text {res }}$. The empirical results are little affected if $y$ and a trend enter freely. For instance, if (17) is estimated unrestrictedly, the coefficient on the trend $(-0.000515)$ is approximately equal to minus the coefficient on $y_{t-1}$ (0.0769) multiplied by the regression coefficient of $y$ on a trend (e.g., 0.00694 from equation (5)). The role of the unrestricted trend is solely to detrend $y_{t-1}$, and the regression coefficient on $y_{t-1}$ is interpretable as the effect on inflation of a deviation of $y_{t-1}$ from its trend. Also, while potential output is estimated in (5) by a linear time trend, the results are not sensitive to its specification as such or as (e.g.) the trend generated by a Hodrick-Prescott filter of $y$.

Conceptually, $y^{\text {res }}$ is more a measure of a demand gap than of an output gap because $Y$ is private final demand rather than (e.g.) GDP. Constructed measures of a gap from the two variables are very similar, and the choice of GDP rather than private final demand makes little difference to the estimated equations. Because private final demand is commonly used in Australia for assessing the state of the domestic business cycle, the former was selected to calculate $y^{\text {res }}$, rather than GDP. The phrase "output gap" is then a convenient but slightly misleading label for $y^{\text {res }}$.

In the ECM (17), the output gap $y^{\text {res }}$ is included to capture the effect on inflation of deviations of output from potential. The effect of the business cycle on inflation, however, may also depend upon how strong recent growth in the economy has been. To illustrate, consider the two points $W$ and $Z$ in Figure A4, which plots quarterly inflation at annual rates and the output gap $y^{r e s}$. The values of actual $y$ relative to trend are equal at $W$ and $Z$, even while the points $W$ and $Z$ are at different stages of the cycle. At $W, y^{r e s}$ has come off its peak and is falling but inflationary pressures may still remain. At $Z, y^{\text {res }}$ has recovered from its trough but inflationary pressures may be slow to resurface. In short, inflationary pressures may tend to lag the cycle, in which case the change in the output gap $\Delta y^{r e s}$ as well as its level $y^{r e s}$ may contain information about inflation. 
Figure A4: The output gap $y^{\text {res }}(-)$, and the underlying inflation rate $\Delta p_{t}$ at annual rates $(\cdots)$.

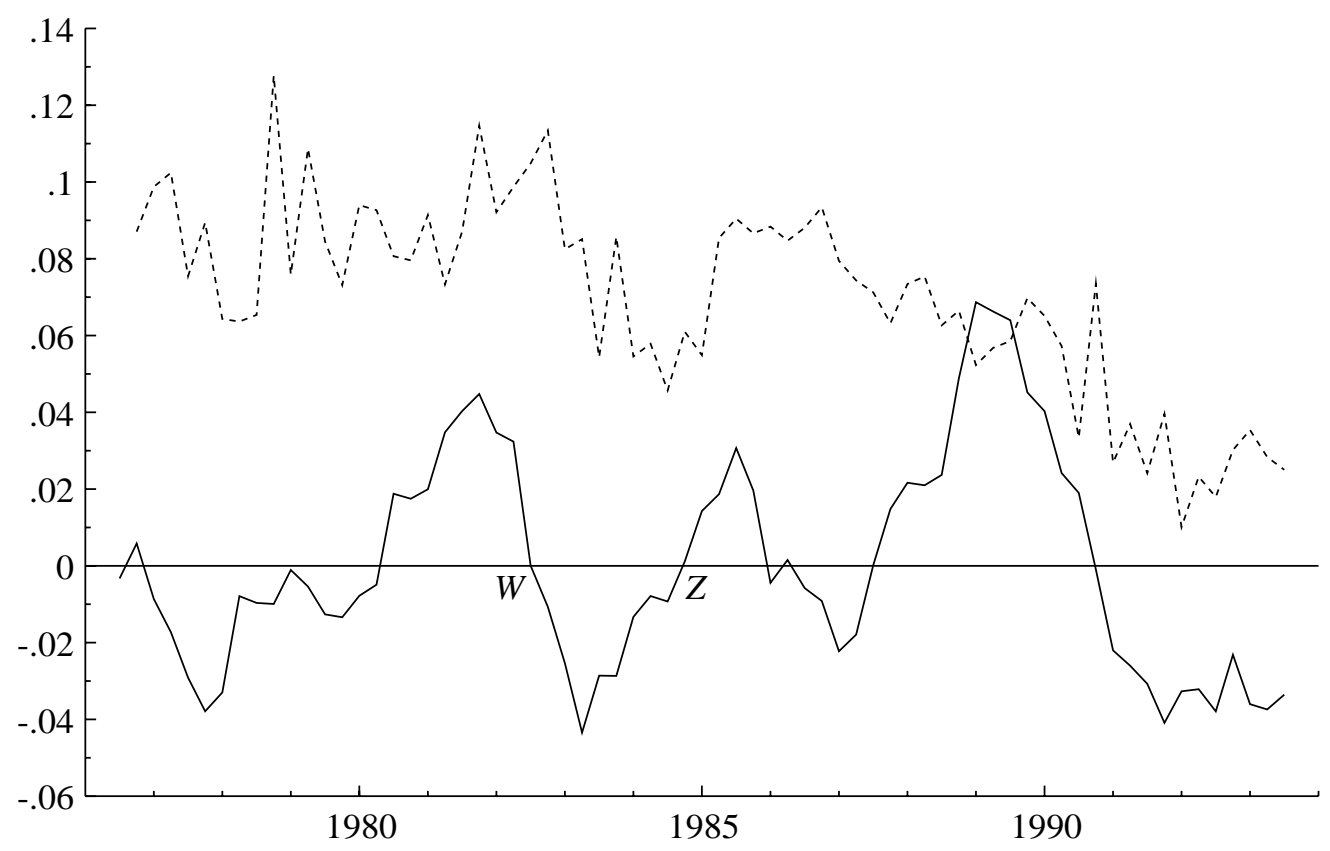

This additional effect of the cycle may be incorporated into the ECM (17) by adding the growth rate of private final demand, noting that $\Delta y$ and $\Delta y^{r e s}$ differ by only a constant. The results are presented below in (A1), where the growth rate in private final demand is annual $\left(\Delta_{4} y_{t}\right)$. This variable is statistically significant, with a negative coefficient as expected.

$$
\begin{aligned}
& \widehat{\Delta p}_{t}=+\underset{[0.0059]}{0.0136} \Delta \text { pet }_{t}+\underset{[0.0091]}{0.0861} y_{t-1}^{\text {res }}-\underset{[0.011]}{0.029 \Delta_{4} y_{t}} \\
& -\underset{[0.0064]}{0.0357}(p-u l c)_{t-1}-\underset{[0.0035]}{0.0428}(p-i p)_{t-1} \\
& -\underset{[0.0020]}{0.0080}(p-p e t)_{t-1}+\underset{(0.0027)}{0.0106} D_{t}+\underset{[0.00066]}{0.00787} \\
& -\underset{[0.0009]}{0.0016} S_{1 t}-\underset{0.00010]}{0.000} S_{2 t}-\underset{[0.0009]}{0.0020} S_{3 t} \\
& T=65[1977(3)-1993(3)] \quad R^{2}=0.88 \quad \hat{\sigma}=0.239 \%
\end{aligned}
$$

The specification in (A1) explains the data somewhat better than the ECM (17), but at the expense of slightly greater complexity. 
Some explanation is required to account for the performance of (17) in spite of its omission of $\Delta_{4} y_{t}$. Four quarterly growth rates comprise $\Delta_{4} y_{t}$ : $\Delta y_{t}, \Delta y_{t-1}, \Delta y_{t-2}$, and $\Delta y_{t-3}$. Only one quarterly growth rate $\left(\Delta y_{t}\right)$ is statistically significant if added to (17), and jointly these growth rates are statistically insignificant. However, the growth rates are statistically significant when their coefficients are imposed to be equal. The sequential reduction in Appendix 2 failed to detect the presence of $\Delta_{4} y_{t}$ because each of the first three reductions dropped the longest lag on all variables, rather than (e.g.) focusing on the lags of a given variable, one variable at a time. Equally, $\Delta_{4} y_{t}$ could only marginally improve the fit of (17), given the ease with which the sequential reduction in Appendix 2 excluded it.

The model in (17) is the focus of the paper because it is slightly more parsimonious than (A1) and with little loss of fit. Both models have very similar statistical properties and economic interpretations. While the point estimates of the long-run elasticities from (A1) are different from those obtained earlier, they are not statistically significantly so. For forecasting in the contemporary economic environment, the effect of the higher import price coefficient in (A1) would be offset by the lower inflationary pressure associated with recovery (through the term $\Delta_{4} y_{t}$ ). 
REFERENCES

Banerjee, A., J.J. Dolado, J.W. Galbraith and D.F. Hendry (1993), Co-integration, Error Correction, and the Econometric Analysis of Nonstationary Data, Oxford University Press, Oxford.

Banerjee, A., J.J. Dolado, D.F. Hendry and G.W. Smith (1986), "Exploring Equilibrium Relationships in Econometrics through Static Models: Some Monte Carlo Evidence", Oxford Bulletin of Economics and Statistics, 48(3), pp. 253-277.

Blundell-Wignall, A. (ed.) (1992), Inflation, Disinflation and Monetary Policy, Reserve Bank of Australia, Sydney.

Boswijk, H.P. (1995), "Efficient Inference on Cointegration Parameters in Structural Error Correction Models", Journal of Econometrics, 69(1), pp. 133-158.

Box, G.E.P. and D.A. Pierce (1970), "Distribution of Residual Autocorrelations in Autoregressive-integrated Moving Average Time Series Models", Journal of the American Statistical Association, 65(332), pp. 1509-1526.

de Brouwer, G., I. Ng and R. Subbaraman (1993), "The Demand for Money in Australia: New Tests on an Old Topic", Reserve Bank of Australia, Sydney, Research Discussion Paper No. 9314.

Brown, R.L., J. Durbin and J.M. Evans (1975), "Techniques for Testing the Constancy of Regression Relationships over Time", Journal of the Royal Statistical Society, Series B, 37(2), pp. 149-192 (with discussion).

Campos, J. (1992), "Confidence Intervals for Linear Combinations of Forecasts from Dynamic Econometric Models", Journal of Policy Modeling, 14(4), pp. 535-560.

Campos, J., N.R. Ericsson and D.F. Hendry (1996), "Cointegration Tests in the Presence of Structural Breaks", Journal of Econometrics, 70(1), in press. 
Chong, Y.Y. and D.F. Hendry (1986), "Econometric Evaluation of Linear Macro-economic Models", Review of Economic Studies, 53(4), pp. 671690.

Chow, G.C. (1960), "Tests of Equality between Sets of Coefficients in Two Linear Regressions", Econometrica, 28(3), pp. 591-605.

Coelli, M. and J. Fahrer (1992), "Indicators of Inflationary Pressure", Reserve Bank of Australia, Sydney, Research Discussion Paper No. 9207.

Cox, D.R. (1961), "Tests of Separate Families of Hypotheses" in J. Neyman (ed.) Proceedings of the Fourth Berkeley Symposium on Mathematical Statistics and Probability, Berkeley, University of California Press, Volume 1, pp. 105-123.

Cox, D.R. (1962), "Further Results on Tests of Separate Families of Hypotheses", Journal of the Royal Statistical Society, Series B, 24(2), pp. 406424.

Davidson, J.E.H., D.F. Hendry, F. Srba and S. Yeo (1978), "Econometric Modelling of the Aggregate Time-series Relationship between Consumers' Expenditure and Income in the United Kingdom", Economic Journal, 88(352), pp. 661-692.

Dickey, D.A. and W.A. Fuller (1981), "Likelihood Ratio Statistics for Autoregressive Time Series with a Unit Root", Econometrica, 49(4), pp. 1057-1072.

Doornik, J.A. and H. Hansen (1994), "A Practical Test for Univariate and Multivariate Normality", Nuffield College, Oxford, England, mimeo.

Doornik, J.A. and D.F. Hendry (1994), PcGive Professional 8.0: An Interactive Econometric Modelling System, International Thomson Publishing, London.

Duesenberry, J. (1950), "The Mechanics of Inflation", Review of Economics and Statistics, 32(2), pp. 144-149. 
Dufour, J.-M. (1982), "Recursive Stability Analysis of Linear Regression Relationships: An Exploratory Methodology", Journal of Econometrics, 19(1), pp. 31-76.

Durbin, J. and G.S. Watson (1950), "Testing for Serial Correlation in Least Squares Regression. I", Biometrika, 37(3/4), pp. 409-428.

Durbin, J. and G.S. Watson (1951), "Testing for Serial Correlation in Least Squares Regression. II”, Biometrika, 38(1/2), pp. 159-178.

Dwyer, J. and R. Lam (1994), "Explaining Import Price Inflation: A Recent History of Second Stage Pass-Through", Reserve Bank of Australia, Sydney, Research Discussion Paper No. 9407.

Dwyer, J. and J. Romalis (1995), "Exposure to Trade and Price-Setting Behaviour: The Australian Experience", Reserve Bank of Australia, Sydney, mimeo.

Engle, R.F. (1982), “Autoregressive Conditional Heteroscedasticity with Estimates of the Variance of United Kingdom Inflation", Econometrica, 50(4), pp. 987-1007.

Engle, R.F. and C.W.J. Granger (1987), "Co-integration and Error Correction: Representation, Estimation, and Testing", Econometrica, 55(2), pp. 251-276.

Engle, R.F. and D.F. Hendry (1993), "Testing Super Exogeneity and Invariance in Regression Models", Journal of Econometrics, 56(1/2), pp. 119-139.

Ericsson, N.R. (1983), "Asymptotic Properties of Instrumental Variables Statistics for Testing Non-nested Hypotheses", Review of Economic Studies, 50(2), pp. 287-304.

Ericsson, N.R. (1986), "Post-simulation Analysis of Monte Carlo Experiments: Interpreting Pesaran's (1974) Study of Non-nested Hypothesis Test Statistics”, Review of Economic Studies, Econometrics Special Issue, 53(4), pp. 691-707. 
Ericsson, N.R. (1994), "Models of the U.S. CPI", Board of Governors of the Federal Reserve System, Washington, D.C., July, mimeo.

Ericsson, N.R. (1995), "Conditional and Structural Error Correction Models", Journal of Econometrics, 69(1), pp. 159-171.

Ericsson, N.R., J. Campos and H.-A. Tran (1990), "PC-GIVE and David Hendry's Econometric Methodology", Revista de Econometria, 10(1), pp. 7-117.

Ericsson, N.R. and D.F. Hendry (1989), "Encompassing and Rational Expectations: How Sequential Corroboration Can Imply Refutation", Board of Governors of the Federal Reserve System, Washington, D.C., June, International Finance Discussion Paper No. 354.

Ericsson, N.R., D.F. Hendry and H.-A. Tran (1994), "Cointegration, Seasonality, Encompassing, and the Demand for Money in the United Kingdom", Chapter 7 in C.P. Hargreaves (ed.) Nonstationary Time Series Analysis and Cointegration, Oxford, Oxford University Press, pp. 179224.

Ericsson, N.R., J.S. Irons and R.W. Tryon (1993), "Output and Inflation in the Long Run", Board of Governors of the Federal Reserve System, Washington, D.C., September, mimeo.

Fahrer, J. and J. Myatt (1991), "Inflation in Australia: Causes, Inertia and Policy", Reserve Bank of Australia, Sydney, Research Discussion Paper No. 9105.

Favero, C. and D.F. Hendry (1992), "Testing the Lucas Critique: A Review", Econometric Reviews, 11(3), pp. 265-306.

Franz, W. and R.J. Gordon (1993), "German and American Wage and Price Dynamics: Differences and Common Themes", European Economic Review, 37(4), pp. 719-762 (with discussion).

Godfrey, L.G. (1978), “Testing Against General Autoregressive and Moving Average Error Models when the Regressors Include Lagged Dependent 
Variables", Econometrica, 46(6), pp. 1293-1301.

Harvey, A.C. (1981), The Econometric Analysis of Time Series, Philip Allan, Oxford.

Hendry, D.F. (1988), "The Encompassing Implications of Feedback versus Feedforward Mechanisms in Econometrics", Oxford Economic Papers, 40(1), pp. 132-149.

Hendry, D.F. (1995), Dynamic Econometrics, Oxford University Press, Oxford.

Hendry, D.F. and J.A. Doornik (1994), "Modelling Linear Dynamic Econometric Systems", Scottish Journal of Political Economy, 41(1), pp. 1-33.

Hendry, D.F. and G.E. Mizon (1993), "Evaluating Dynamic Econometric Models by Encompassing the VAR", Chapter 18 in P.C.B. Phillips (ed.) Models, Methods, and Applications of Econometrics, Cambridge, Massachusetts, Basil Blackwell, pp. 272-300.

Hendry, D.F., A.R. Pagan and J.D. Sargan (1984), "Dynamic Specification", Chapter 18 in Z. Griliches and M.D. Intriligator (eds.) Handbook of Econometrics, Amsterdam, North-Holland, Volume 2, pp. 1023-1100.

Hylleberg, S. (ed.) (1992), Modelling Seasonality, Oxford University Press, Oxford.

Jarque, C.M. and A.K. Bera (1980), "Efficient Tests for Normality, Homoscedasticity and Serial Independence of Regression Residuals", Economics Letters, 6(3), pp. 255-259.

Johansen, S. (1988), "Statistical Analysis of Cointegration Vectors", Journal of Economic Dynamics and Control, 12(2/3), pp. 231-254.

Johansen, S. (1991), "Estimation and Hypothesis Testing of Cointegration Vectors in Gaussian Vector Autoregressive Models", Econometrica, 59(6), pp. 1551-1580. 
Johansen, S. (1992a), "Cointegration in Partial Systems and the Efficiency of Single-equation Analysis", Journal of Econometrics, 52(3), pp. 389402.

Johansen, S. (1992b), "An I(2) Cointegration Analysis of the Purchasing Power Parity between Australia and the United States", Chapter 9 in C.P. Hargreaves (ed.) Macroeconomic Modelling in the Long Run, Aldershot, Hants., England, Edward Elgar, pp. 229-248.

Johansen, S. (1992c), "Testing Weak Exogeneity and the Order of Cointegration in UK Money Demand Data”, Journal of Policy Modeling, 14(3), pp. 313-334.

Johansen, S. and K. Juselius (1990), "Maximum Likelihood Estimation and Inference on Cointegration - With Applications to the Demand for Money", Oxford Bulletin of Economics and Statistics, 52(2), pp. 169-210.

Juselius, K. (1992), "Domestic and Foreign Effects on Prices in an Open Economy: The Case of Denmark", Journal of Policy Modeling, 14(4), pp. 401-428.

Juselius, K. (1993), "VAR Modelling and Haavelmo's Probability Approach to Macroeconomic Modelling", Empirical Economics, 18(4), pp. 595-622.

Kamin, S.B. and N.R. Ericsson (1993), "Dollarization in Argentina", Board of Governors of the Federal Reserve System, Washington, D.C., November, International Finance Discussion Paper No. 460.

Knight, G. (1992), "Inflation in Australia: An Empirical Case Study", Honours Thesis (Department of Economics), University of Sydney, Sydney, Australia.

Kremers, J.J.M., N.R. Ericsson and J.J. Dolado (1992), "The Power of Cointegration Tests", Oxford Bulletin of Economics and Statistics, 54(3), pp. 325-348.

MacKinnon, J.G. (1991), “Critical Values for Cointegration Tests”, Chap- 
ter 13 in R.F. Engle and C.W.J. Granger (eds.) Long-run Economic Relationships: Readings in Cointegration, Oxford, Oxford University Press, pp. 267-276.

MacKinnon, J.G. and H. White (1985), "Some Heteroskedasticityconsistent Covariance Matrix Estimators with Improved Finite Sample Properties", Journal of Econometrics, 29(3), pp. 305-325.

McTaggart, D. and T. Hall (1993), “'Unemployment: Macroeconomic Causes and Solutions?' Or 'Are Inflation and the Current Account Constraints on Growth?'”, Department of Economics, Bond University, Gold Coast, Australia, Discussion Paper No. 39.

Metin, K. (1994), “An Integrated Analysis of Turkish Inflation”, Department of Economics, Bilkent University, Ankara, Turkey, mimeo.

Mizon, G.E. and J.-F. Richard (1986), "The Encompassing Principle and Its Application to Testing Non-nested Hypotheses", Econometrica, 54(3), pp. 657-678.

Nicholls, D.F. and A.R. Pagan (1983), "Heteroscedasticity in Models with Lagged Dependent Variables", Econometrica, 51(4), pp. 1233-1242.

Nickell, S. (1985), "Error Correction, Partial Adjustment and All That: An Expository Note", Oxford Bulletin of Economics and Statistics, 47(2), pp. 119-129.

Osterwald-Lenum, M. (1992), "A Note with Quantiles of the Asymptotic Distribution of the Maximum Likelihood Cointegration Rank Test Statistics", Oxford Bulletin of Economics and Statistics, 54(3), pp. 461-472.

Pesaran, M.H. (1974), "On the General Problem of Model Selection", Review of Economic Studies, 41(2), pp. 153-171.

Ramsey, J.B. (1969), "Tests for Specification Errors in Classical Linear Least-squares Regression Analysis", Journal of the Royal Statistical Society, Series B, 31(2), pp. 350-371. 
Reserve Bank of Australia (1994a), 1994 Report and Financial Statements, Reserve Bank of Australia, Sydney.

Reserve Bank of Australia (1994b), "Measuring 'Underlying' Inflation", Reserve Bank of Australia Bulletin, August, pp. 1-6.

Richards, T. and G. Stevens (1987), "Estimating the Inflationary Effects of Depreciation", Reserve Bank of Australia, Sydney, Research Discussion Paper No. 8713.

Sargan, J.D. (1958), "The Estimation of Economic Relationships Using Instrumental Variables", Econometrica, 26(3), pp. 393-415.

Smith, G.W. (1986), "A Dynamic Baumol-Tobin Model of Money Demand", Review of Economic Studies, 53(3), pp. 465-469.

White, H. (1980), "A Heteroskedasticity-consistent Covariance Matrix Estimator and a Direct Test for Heteroskedasticity", Econometrica, 48(4), pp. 817-838. 